\title{
Gallium-Enhanced Aluminum and Copper Electromigration Performance for Flexible Electronics
}

\author{
Saeedeh Ravandi, Alexey Minenkov, Cezarina Cela Mardare, Jan Philipp Kollender, Heiko Groiss,
} Achim Walter Hassel, and Andrei Ionut Mardare*

Cite This: ACS Appl. Mater. Interfaces 2021, 13, 6960-6974

Read Online

\section{ACCESS |}

Џlll Metrics \& More

ABSTRACT: Wide range binary and ternary thin film combinatorial libraries mixing $\mathrm{Al}, \mathrm{Cu}$, and $\mathrm{Ga}$ were screened for identifying alloys with enhanced ability to withstand electromigration. Bidimensional test wires were obtained by lithographically patterning the substrates before simultaneous vacuum codeposition from independent sources. Current-voltage measurement automation allowed for high throughput experimentation, revealing the maximum current density and voltage at the electrical failure threshold for each alloy. The grain boundary dynamic during electromigration is attributed to the resultant between the force corresponding to the electron flux density and the one corresponding to the atomic concentration gradient perpendicular to the current flow direction. The screening identifies $\mathrm{Al}-8$ at. \% Ga

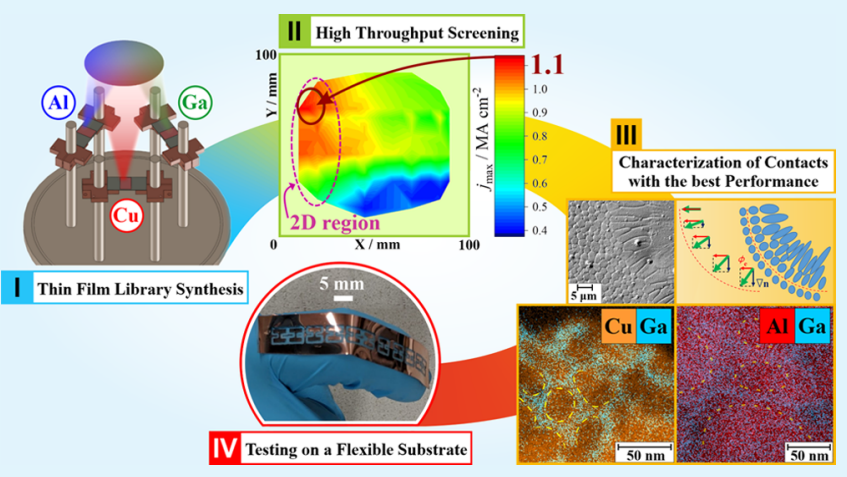
and $\mathrm{Cu}-5$ at. \% Ga for replacing pure $\mathrm{Al}$ or $\mathrm{Cu}$ connecting lines in high current/power electronics. Both alloys were deposited on polyethylene naphthalate (PEN) flexible substrates. The film adhesion to PEN is enhanced by alloying $\mathrm{Al}$ or $\mathrm{Cu}$ with $\mathrm{Ga}$. Electrical testing demonstrated that $\mathrm{Al}-8$ at. \% Ga is more suitable for conducting lines in flexible electronics, showing an almost $50 \%$ increase in electromigration suppression when compared to pure $\mathrm{Al}$. Moreover, $\mathrm{Cu}-5$ at. \% Ga showed superior properties as compared to pure $\mathrm{Cu}$ on both $\mathrm{SiO}_{2}$ and $\mathrm{PEN}$ substrates, where more than $100 \%$ increase in maximum current density was identified.

KEYWORDS: metallic thin films, combinatorial libraries, high throughput screening, low resistance alloys, flexible electronics

\section{INTRODUCTION}

One of the prominent goals of modern electronics advancement is to address the need for flexible devices in various sectors of daily life, starting with avoiding the replacement of forever-broken mobile phone displays and finishing with using thin sensor foils in direct contact with human skin. ${ }^{1-3}$ Progress in this field is vital for development of health monitoring devices, soft implants, soft robotics, and an overall notable increase in plastic bioelectronics. ${ }^{4-9}$ Such applications make use not only of the flexibility but also on the ability to stretch the substrates leading to extreme mechanical gradients. ${ }^{10-13} \mathrm{~A}$ smart step in the further evolution of stretchable and soft electronics is defined by the use of liquid metals such as $\mathrm{Ga}^{14-17}$ The required flexibility of these devices originates primarily from the use of thin films in fabrication of active and passive components combined with the employment of flexible polymeric substrates such as polyethylene naphthalate (PEN). ${ }^{18-20}$

Considering the bidimensional nature of thin and ultrathin films, even low electrical currents flowing through a device may induce electromigration in the conducting path through which the electron flux passes. ${ }^{21-23}$ This type of atomic migration is well-known from the appearance of first electronic circuits and is continuously present in modern thin film-based devices. ${ }^{24,25}$ As an extension of Joule's law grounded in the electronphonon interaction, high electron fluxes lead to a direct displacement of atoms forming the conducting path, disregarding the nature of the substrate on which such a path is patterned. As a result, the conducting path is eventually interrupted by atomic migration in the direction of the electron flow and surface void migration in the opposite direction, leading to a total device failure. ${ }^{26}$ This type of device failure is currently recognized mainly in high current/power electronics. However, the broadening of the flexible device application range (due to the continuous trend of replacing Si-based devices with flexible ones) combined with the increased use of ultrathin films may demand, in the near future, the overcoming of the limitations regarding the maximum current densities applicable in flexible electronics.

Received: December 15, 2020

Accepted: January 14, 2021

Published: January 25, 2021 
Both $\mathrm{Al}$ and $\mathrm{Cu}$ are largely used in the electronic industry for interconnecting various parts of circuitry. ${ }^{27-29}$ Their low electrical conductivity and cost define their technological relevance. Mixing both metals in search for more stable interconnects was studied in both bulk and thin film forms, and no exceptional enhancements of ability to withstand electromigration emerged. ${ }^{30-32}$ An increase in the electrical resistivity of $\mathrm{Al}-\mathrm{Cu}$ alloys raised concerns requiring a trade-off between resistivity and electromigration reliability to be found. ${ }^{31}$ Alternatively, different alloying elements may be used in combination with $\mathrm{Al}$ and/or $\mathrm{Cu}$ for improving the electrical behavior of conducting lines. Species with large atomic sizes (such as rare earths) may be considered in an attempt to increase the entropy of $\mathrm{Al}$ or $\mathrm{Cu}$ thin film alloys, decreasing the total grain boundary area on the surface and thus restricting void formation. ${ }^{32}$ Gallium can also be such an alloying element. Pure Ga has a very low melting temperature of 29.8 ${ }^{\circ} \mathrm{C}$ and is highly soluble in $\mathrm{Al}$, up to 20 wt \% (9 at. \%) under standard conditions. ${ }^{33}$ It influences the grain boundaries of polycrystalline $\mathrm{Al}^{34,35}$ by a rather unique mechanism described as grain boundary wetting. ${ }^{36,37}$ From this point of view, the use of $\mathrm{Ga}$ as an alloying element represents a conceptual advance for these special alloys from the point of stability of polycrystalline metal films at continuous bending. Although $\mathrm{Ga}$ is in principle known to deteriorate the corrosion resistance of $\mathrm{Al}$, for low to moderate concentrations of $\mathrm{Ga}$, a reasonable corrosion resistance is achieved. ${ }^{38-40}$ The $\mathrm{Cu}-\mathrm{Ga}$ system seems to be promising as a low-temperature $\mathrm{Pb}$-free solder ${ }^{41}$ and is a crucial part of $\mathrm{Cu}-\mathrm{In}-\mathrm{Ga}-\mathrm{Se}$ thin film solar cells. ${ }^{42}$ Because $\mathrm{Ga}$ and most of its liquid metal alloys do not display any known toxic reactions, ${ }^{43,44}$ their application in flexible and skin-contact electronics is already under study. ${ }^{45-47}$ The electromigration effects in these materials when used as liquid interconnects already came into scientific focus. ${ }^{48,49}$ Gallium shows an exceptional phase transformation behavior as it has an extremely low melting point and a very high boiling point due to the formation of Ga-dimers which are also responsible for the density anomaly. ${ }^{50}$ The latter one can compensate the alloying partner $(\mathrm{Al}$ or $\mathrm{Cu}$ ) and reduce the temperature dependence of the density.

The current study focuses on the identification of Al- and $\mathrm{Cu}$-based solid alloys with superior electrical properties, obtained by mixing them with $\mathrm{Ga}$, employing high throughput screening of binary and ternary thin film combinatorial libraries on $\mathrm{SiO}_{2}$ substrates. A direct current-voltage analysis of lithographically pre-patterned test wire thin film alloys enables the access to the maximum values of current density and voltage before total electrical failure as a measure of ability to withstand electromigration. The alloys with the best performance identified in the combinatorial screening on $\mathrm{SiO}_{2}$ substrates (according to the $\mathrm{Si}$ technology) are applied on PEN substrates, and initial tests are performed evaluating the possibility of their future implementation in flexible electronics.

\section{EXPERIMENTAL SECTION}

Lithographical Patterning of Test Wires. For electrical screening of thin film combinatorial libraries, test wires were patterned within an area of $5 \times 5 \mathrm{~mm}^{2}$ on the entire available surface of the substrates. The size of each wire was defined as $0.2 \times 1 \mathrm{~mm}^{2}$ coupled to larger pads for electrical connections (see Figure S1). The pattering of the wires was performed using two methods. The use of rigid 4" $\mathrm{SiO}_{2}$ wafers as substrates allowed a lithographic process while testing selected alloys on flexible PEN substrates involved a direct writing process. Both lithographic steps were performed before metallic thin film deposition.

An EVG101 (EVG, Austria) spin coater was used at $2000 \mathrm{rpm}$ for coating $\mathrm{SiO}_{2}$ wafers for $60 \mathrm{~s}$ with a negative photoresist (AZnLOF 2070). The chosen parameters resulted in an uniform resist film with an approximate thickness of $9.5 \mu \mathrm{m}$. Definition of the test wire structures for the lift-off process was done using a foil-based mask. The photolithographic process was performed on an EVG620 (EVG, Austria) mask aligner. Dedicated tooling for the foil based mask was used to accomplish defined negative side wall angles and a proximity gap of $20 \mu \mathrm{m}$. The resist was exposed to UV light at $365 \mathrm{~nm}$ with a fluence of $300 \mathrm{~mJ} \mathrm{~cm}^{-2}$. A post exposure heat treatment at $110^{\circ} \mathrm{C}$ for $60 \mathrm{~s}$ was applied in order to finalize the crosslinking induced by the UV irradiation. Developing the resist was done in an AZ $726 \mathrm{MiF}$ bath for $240 \mathrm{~s}$. More details about the wire sizing and design were previously reported. ${ }^{51}$ Following this route, more than 300 wires were pre-patterned uniformly distributed on each processed $\mathrm{SiO}_{2}$ wafer (see Figure S1). After thin film deposition, the lift-off procedure was performed using NG101 (MicroChemicals, Germany) etchant/ removal solution.

A direct writing approach was chosen for patterning of test wires on PEN substrates, mainly due to the difficulty of uniformly spin coating these flexible surfaces. For this purpose, a permanent Edding marker with a tip diameter below $0.5 \mathrm{~mm}$ was attached to an automatized $X Y Z$ stage. A force sensor attached to the $Z$ axis was responsible for controlling the pressure of the marker tip on the polymer foil during drawing. Using LabVIEW, the stage was programed to draw the contour of multiple test wires on areas in the size of a microscope slide $\left(25 \times 76 \mathrm{~mm}^{2}\right)$. Additional information can be found elsewhere. ${ }^{51}$ After metallization, the lift-off procedure was performed using ethanol.

Thin Film Deposition and Characterization. Binary Al-Ga and $\mathrm{Cu}-\mathrm{Ga}$ as well as the ternary $\mathrm{Al}-\mathrm{Cu}-\mathrm{Ga}$ thin film combinatorial libraries were deposited on $\mathrm{SiO}_{2}$ and PEN substrates by physical vapor deposition at room temperature for avoiding thermally activated interspecies diffusion. Additionally, selected binary alloys and pure metals were separately deposited. The $\mathrm{SiO}_{2}$ wafers were used directly after developing the photoresist, without further processing. The PEN substrates were first degreased and then rinsed with ethanol and deionized water before direct writing patterning. High purity $\mathrm{Al}$, $\mathrm{Cu}$ (99.995\%, Alfa Aesar), and Ga (99.999\%, Alfa Aesar) were loaded into three independent $\mathrm{W}$ evaporation boats. Co-evaporation from these sources allowed formation of combinatorial alloys. Evaporation from single sources was performed as well for pure metal samples. The deposition chamber had a base pressure in the range of $10^{-5} \mathrm{~Pa}$. Each of the $\mathrm{W}$ boats was monitored by a quartz crystal microbalance (QCM-INFICON) for in situ feedback regarding individual evaporation rates. This information was used when defining the compositional spreads in binary and ternary libraries as well as the selected binary compositions. In order to obtain improved thickness uniformity and a single composition, selected binary alloys were deposited while rotating the substrate with $5 \mathrm{rpm}$. All libraries were deposited without rotation. For the main species $\mathrm{Al}$ and $\mathrm{Cu}$ in the libraries, deposition rates between 0.7 and $1 \mathrm{~nm} \mathrm{~s}^{-1}$ were used while lower amounts of Ga were controlled by using deposition rates at least 10 times smaller. During library deposition, the evaporation rates of constituent species were always kept constant for ensuring local indepth compositional uniformity. Overall, the deposited thin film thickness was in the range of $300 \mathrm{~nm}$ for alloys and pure elements on different substrates.

After deposition, each thin film library was moved in vacuum by a robotic arm (Kurt J. Lesker) from the deposition chamber to a selfdeveloped scanning energy dispersive X-ray spectroscopy (SEDX) chamber. The system is designed to scan through the entire surface automatically and map the compositional spread on the substrates. IDFix software (remX GmbH) was used for quantitative analysis of the test wires uniformly distributed across the substrate. A Si drift detector (SDD, remX GmbH) was used for the detection of X-rays resulting from locally irradiating the surface with $20 \mathrm{keV}$ electrons. Due to the large irradiation spot $(500 \mu \mathrm{m})$, the compositional errors 

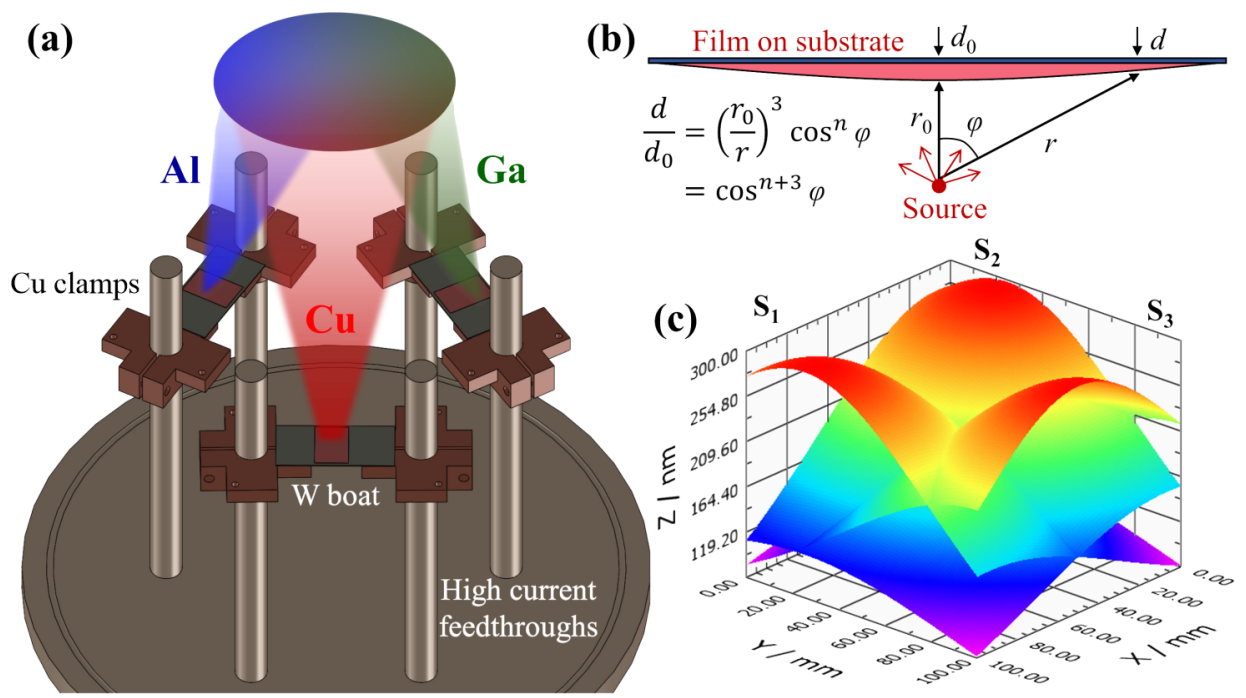

Figure 1. Principle of co-evaporation with vapor phase species mixing (a), cosine law of evaporation from a single source (b), and the 3D result of composition/thickness profiles for ternary libraries (c).

are in the range of \pm 0.5 at. \%. The SEDX compositional mapping was used for identifying individual test wires on each $\mathrm{SiO}_{2}$ wafer.

The thickness of individual test wires after metallization was measured by contact profilometry (Dektak XT Vision 64, Bruker). The surface morphology of Ga-based alloys and pure elements on different substrates was evaluated by scanning electron microscopy (SEM) using a ZEISS CrossBeam $1540 \mathrm{XB}$ microscope with in-lens detection. Films deposited on $\mathrm{SiO}_{2}$ were imaged using acceleration voltages up to $10 \mathrm{kV}$. For avoiding permanent substrate damage, films deposited on PEN were imaged using $1 \mathrm{kV}$ acceleration voltage only. Crystallographic characteristics of individual alloys across the Galibraries were studied by X-ray diffraction (XRD). For this purpose, a Philips X'Pert Pro system was used in the Bragg-Brentano geometry. For the binary libraries, a spot size of $5 \times 20 \mathrm{~mm}^{2}$ was employed with the short length parallel to the direction of the concentration gradient and the long one perpendicular to it in order to maximize the volume from which the signal is generated. For the ternary system, a spot size of $5 \times 5 \mathrm{~mm}^{2}$ centered on a wire was used, which also includes parts from the contacting pads found above and below. This was the minimum area which led to a good signal to noise ratio from the thin film, while ensuring a minimal lateral concentration variation. To increase even more the signal, a very low acquisition speed was chosen with a step size of $4.2 \times 10^{-30}$ and a time per step of $80 \mathrm{~s}$ which summed up to $182 \mathrm{~min}$ of measurement time per diffraction pattern. In total, 25 diffractograms were acquired along and across the ternary library.

For deeper insights into the samples morphology and components distribution, we have rigorously utilized high resolution (HR) transmission electron microscopy (TEM) in conjunction with scanning (S)TEM EDX elemental mapping. The chosen Al-Ga and $\mathrm{Cu}-\mathrm{Ga}$ alloy specimens with the best performance synthesized on the PEN substrate were first thinned down to electron transparency. This challenging step was performed by primary dimpling the sample from the PEN substrate side (Dimple Grinder II, Gatan). While final thinning was gently conducted by $\mathrm{Ar}$ ion sputtering with an incident angle of $5^{\circ}$ (precision ion polishing system PIPS 691, Gatan). The applied approach allowed achieving broad regions of free-standing $\mathrm{Al}-\mathrm{Ga}(\mathrm{Cu}-\mathrm{Ga})$ films suitable for in-depth TEM characterization. The investigation was fulfilled in a JEOL JEM2200FS TEM equipped with an in-column $\Omega$-filter and operated at $200 \mathrm{kV}$. Images were recorded applying zero-loss filtering. The microscope was fitted with an EDX detector from Oxford Instruments. Elemental maps were constructed via Aztec software. To distinguish possible beam influences, we have routinely compared the structure of the investigated film area with unexposed neighboring regions after EDX map acquisition. The assessed concentration measurement error was estimated with \pm 1 at. $\% .{ }^{52}$ In the long run, the obtained data on the film structure and components distribution peculiarities were used for the explanation of the observed performance enhancement.

\section{RESULTS AND DISCUSSION}

Thin Film Combinatorial Libraries for Electromigration Testing. In order to assess the dynamic behavior of $\mathrm{Al}$, $\mathrm{Cu}$, and their alloys under high electron fluxes, a standardized design of the test wire is needed to be implemented. ${ }^{51}$ In this way, statistical measurements and reproducibility tests may be easily performed and a comparison between different alloys ability to withstand electromigration becomes straightforward. Different aspect ratios of test wires were explored, and the most suitable design was selected for this study. A projected area of $0.2 \times 1 \mathrm{~mm}^{2}$ provides a stable and reproducible surface, decreasing the patterning errors and optimizing the electrical resistance for attaining electromigration at reasonably low voltages. Using this design, test wires were patterned by a lithographic step preceding the metallic alloy deposition. The entire available surface of the substrate (e.g. rigid $4 " \mathrm{SiO}_{2}$ wafers) was covered during lithography for maximizing the final number of test wires with an identical shape obtained in one library. Once the lithographic step for test wire definition is performed, the substrate is ready for the next step of combinatorial thin film deposition.

Co-evaporation from up to three different sources is schematically described in part (a) of Figure 1. The drawing describes the principles of thermal co-evaporation where three $\mathrm{W}$ boats are connected to external high current power supplies through thick $\mathrm{Cu}$ rods for providing the necessary power for evaporation of each metal in vacuum. The sources are positioned with their center tangent to the substrate in order to maximize the compositional gradient for a larger library. Through the vapor phase mixing of all contributing species, a continuous compositional gradient is achieved. This is directly related to the thickness gradient naturally obtained from a single source due to the cosine law governing thermal evaporation. Schematically, the thickness uniformity dependence on deposition angle $\varphi$ is described in part (b) of Figure 1. One can clearly see that directly above each source, the film 


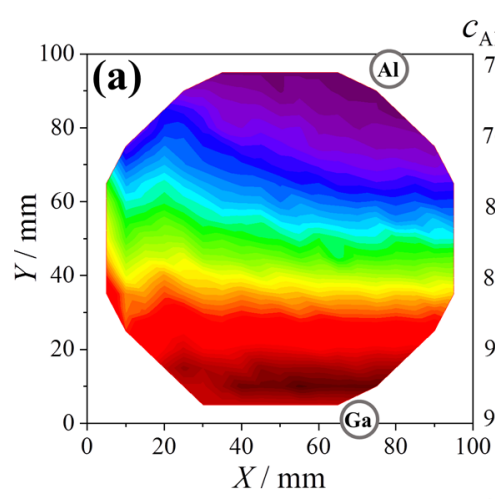

$c_{\mathrm{Al}}$ at. $\% c_{\mathrm{Ga}}$
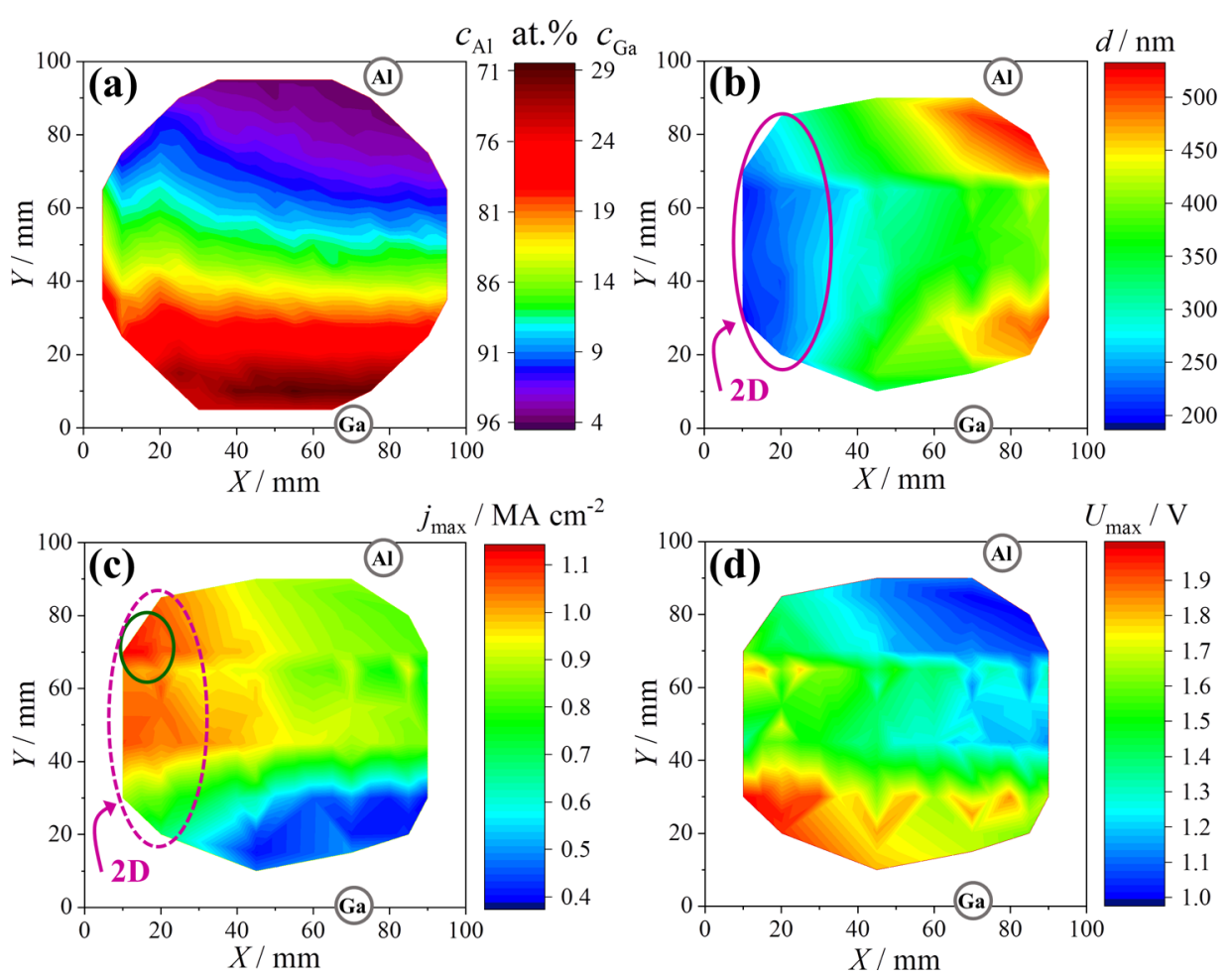

Figure 2. Al-Ga thin film library mappings (with indication of source positions): (a) composition, (b) film thickness with bidimensional region, (c) maximum current density, and (d) maximum voltage.

thickness $d$ increases as compared to the substrate edges, following the cosine law. In an obvious manner, the cosine of the deposition angle is related to the deposition distance $r$ for various locations along the substrate. When used independently (one at a time), each source produces a $3 \mathrm{D}$ thickness profile on the substrate surface and a cross-section through this profile is, in particular, visible in Figure $1 \mathrm{~b}$. When used concomitantly, all deposition sources mix their individual profiles in a manner suggested by the simulated 3D surfaces in Figure 1c. The through-thickness composition at a given location remains constant, as defined by the individual evaporation rates and deposition angle, while the lateral composition across the library changes. For simplicity reasons, the exemplary surfaces were calculated here with identical deposition rates, identical deposition distances, and a cosine coefficient $n=1$ describing an ideal point source.

In summary, Figure 1 describes the entire co-deposition process and evidences the fact that alloys obtained by mixing two or three species will have different thicknesses, a fact which cannot be directly controlled during the deposition process but needs to be evaluated afterward. During co-deposition, only the deposition rate is controlled via the electrical power supplied to each source and this allows a compositional control across the library. However, for electromigration testing, the maximum current density passing through one wire before its electrical failure is relevant. For this reason, each electrically tested wire from libraries in this study has its thickness measured by contact profilometry in order to obtain the accurate cross sectional area.

An optical image of a $\mathrm{SiO}_{2}$ wafer with patterned $\mathrm{Al}-\mathrm{Ga}$ test wire alloys is presented as Supporting Information in Figure S1. Additionally, an enhanced view is given for better observing the details of each wire together with the contact positions of the 4-point electrical testing (current density $j$ vs voltage $U$ ) measuring head. High throughput experimentation is achieved by automatically positioning the $j-U$ head using an automatized $X Y Z$ stage combined with LabVIEW programming and data acquisition. Since the in-plane dimensions of one test wire are much larger than its thickness, all wires may actually be considered as bidimensional (2D), which is a prominent feature of any modern electronic device where conducting paths are in the form of thin and ultrathin films.

Screening of Gallium-Based Binary and Ternary Libraries on $\mathrm{SiO}_{2}$ Substrates. In this study, two technically relevant metals for interconnecting lines in electronic circuitry $(\mathrm{Al}$ and $\mathrm{Cu}$ ) were used in combination with $\mathrm{Ga}$ for searching alloys with improved ability to withstand electromigration. For this purpose, $\mathrm{Al}-\mathrm{Ga}, \mathrm{Cu}-\mathrm{Ga}$ and $\mathrm{Al}-\mathrm{Cu}-\mathrm{Ga}$ thin film combinatorial libraries were deposited on lithographically pre-patterned $\mathrm{SiO}_{2}$ wafers. The first mapping performed is always the compositional one. Using scanning EDX, each library is mapped before electrical measurements. In this way, each surface of a $2 \mathrm{D}$ test wire having a given $X Y$ set of coordinates is directly linked to a certain composition allowing further mapping of properties.

In the Supporting Information, Figure S2 presents a typical set of $j-U$ electrical measurements performed on the $\mathrm{Al}-\mathrm{Ga}$ library along the compositional gradient. For each tested wire, the current is increased until open circuit conditions settle in. This electrical failure occurs due to the interruption of the electron conducting path caused by electromigration of metallic species on the surface. For all $j-U$ curves, a typical shape may be observed. At low current densities, the $j-U$ relationship remains linear according to Ohm's law and no electromigration can be detected. The linear regime usually depends on wire composition and may indicate a current density threshold for a safe electrical use of a given alloy. The shape of $j-U$ curves changes due to the Joule effect when the 

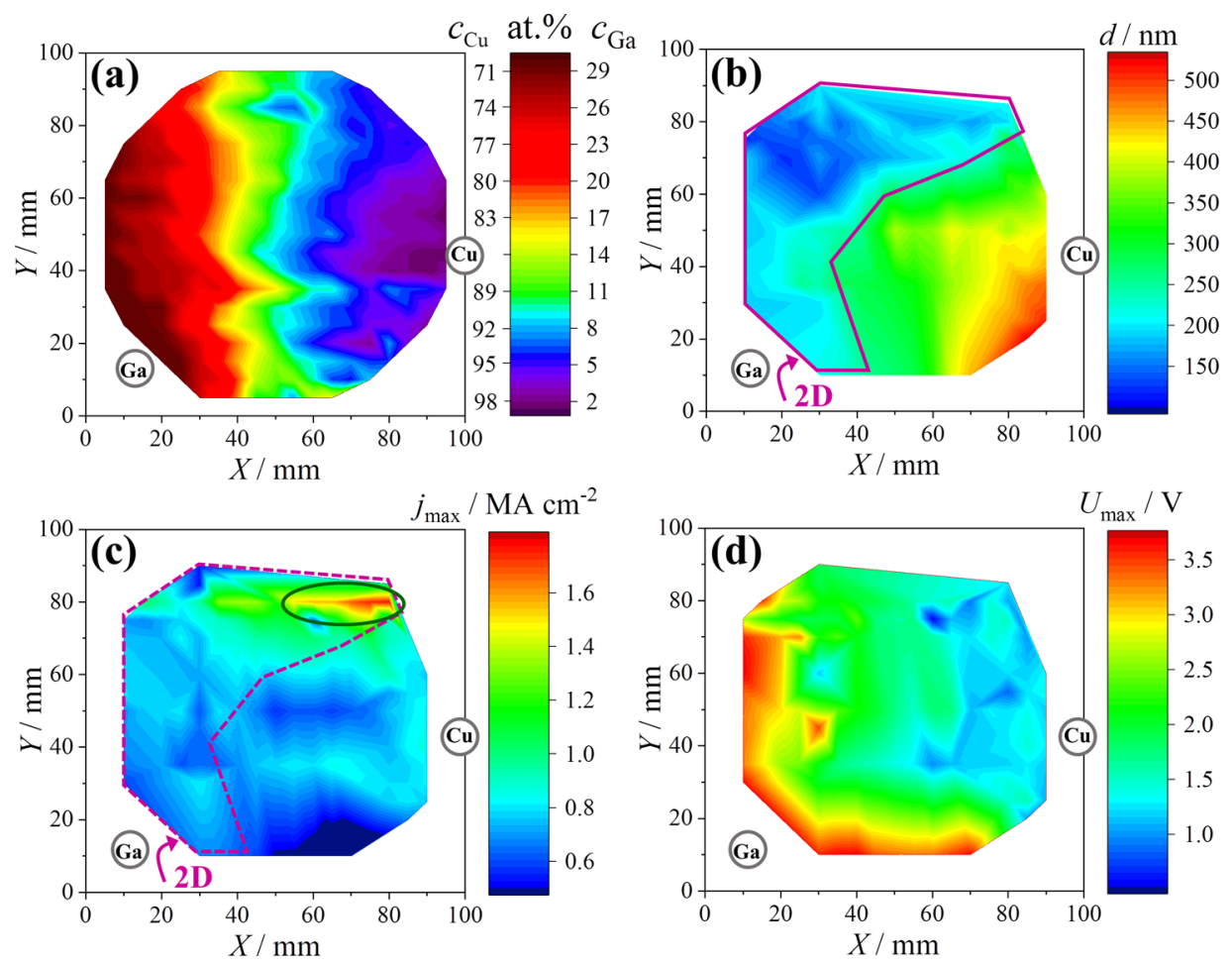

Figure 3. $\mathrm{Cu}-\mathrm{Ga}$ thin film library mappings (with indication of source positions): (a) composition, (b) film thickness with bidimensional region, (c) maximum current density, and (d) maximum voltage.

current density increases beyond the threshold. Increasing the temperature of the wire leads to an increase in the electrical resistance, and the curves start to flatten. Electromigration starts to affect the wire capability of transporting electrons, and eventually, the wire fails. The failing moment gives the maximum values for $j$ and $U$ that are used to characterize the wire ability to withstand electromigration in a compositional mapping.

Such linear mapping is presented as an example also in Figure S2 for the Al-Ga library. Screening such mapping refers to identifying a composition where, for example, the $j_{\max }$ value is the highest. However, since the thickness of the test wires plays a crucial role during the electrical testing and the previously discussed cosine law affects the thickness profile, a surface mapping across the entire wafer is desirable. In a complete surface mapping, the image obtained will be formed by successive line mappings similar to those described in Figure S2.

The results of the properties screening obtained in the AlGa thin film library are presented in Figure 2 as surface color maps. Identifying the composition of the test wires across the surface of the Al-Ga library is easily performed using the EDX mapping presented in Figure 2a. The position of the evaporation sources used can be observed as $\mathrm{Ga}$ on the lower-right corner and $\mathrm{Al}$ on the upper-right corner of the image. The minimum Ga content in the library was slightly below 4 at. \%. Complementarily, the $\mathrm{Al}$ amount ranges between 96 and 71 at. \%. A total compositional spread of 25 at. $\%$ was obtained along the library, which gives a convenient compositional resolution of 0.25 at. $\% \mathrm{~mm}^{-1}$ across the entire wafer. Because each $2 \mathrm{D}$ test wire is patterned within $5 \times 5$ $\mathrm{mm}^{2}$, compositional identification of one single wire can be safely done with a precision of \pm 0.5 at. \%, as typical in such studies. This precision also matches well the precision of the
EDX analysis, and it will be considered for all values further reported in this study.

High throughput measurements of test wire thicknesses performed by contact profilometry allowed the thickness mapping presented in Figure $2 \mathrm{~b}$. Here, the position of the material sources is even better evidenced through the increase in the film thickness. Close to each evaporator (ideally directly above it, as Figure $1 \mathrm{~b}$ shows), the cosine law indicates the thickest films and the surface mapping confirms this. In the vicinity of the Ga source, the library thickness reaches $500 \mathrm{~nm}$ while in the vicinity of the $\mathrm{Al}$ source, the films are even thicker. Interaction between both species in the vapor phase results in the combined surface presented in the figure, with a thickness around $350 \mathrm{~nm}$ at the center of the wafer. On the left side of the $\mathrm{Al}-\mathrm{Ga}$ library, at the furthest distance from both sources, the thin film thickness drops to $200 \mathrm{~nm}$. This natural thickness profile obtained during the film formation is beneficial to the current study, allowing to trace and discuss the effect of film thickness on achievable test wire performance.

In Figure $2 c$, the maximum current density $\left(j_{\max }\right)$ that each tested $2 \mathrm{D}$ wire withstands before total failure is mapped across the $\mathrm{Al}-\mathrm{Ga}$ library surface. The smallest values are observed close to the Ga source. Alloys with the Ga content above 20 at. $\%$ are easily affected by electromigration effects with their $j_{\max }$ values dropping below $0.5 \mathrm{MA} \mathrm{cm}^{-2}$. These values are of no real interest for actual high current applications because a current density as high as $1.3 \mathrm{MA} \mathrm{cm}{ }^{-2}$ could be achieved on pure $\mathrm{Al}$ test wires. ${ }^{32}$ However, diagonally across this region, values of $j_{\max }$ exceeding $1.1 \mathrm{MA} \mathrm{cm}^{-2}$ are observable in the mapping. The $\mathrm{Al}-\mathrm{Ga}$ alloy with the highest ability to withstand electromigration was identified as $\mathrm{Al}-8$ at. \% Ga, having a $j_{\max }$ value of $1.15 \mathrm{MA} \mathrm{cm}^{-2}$. On observing the compositional mapping in Figure 2a, it can be easily seen that there are other positions across the library that also have the 

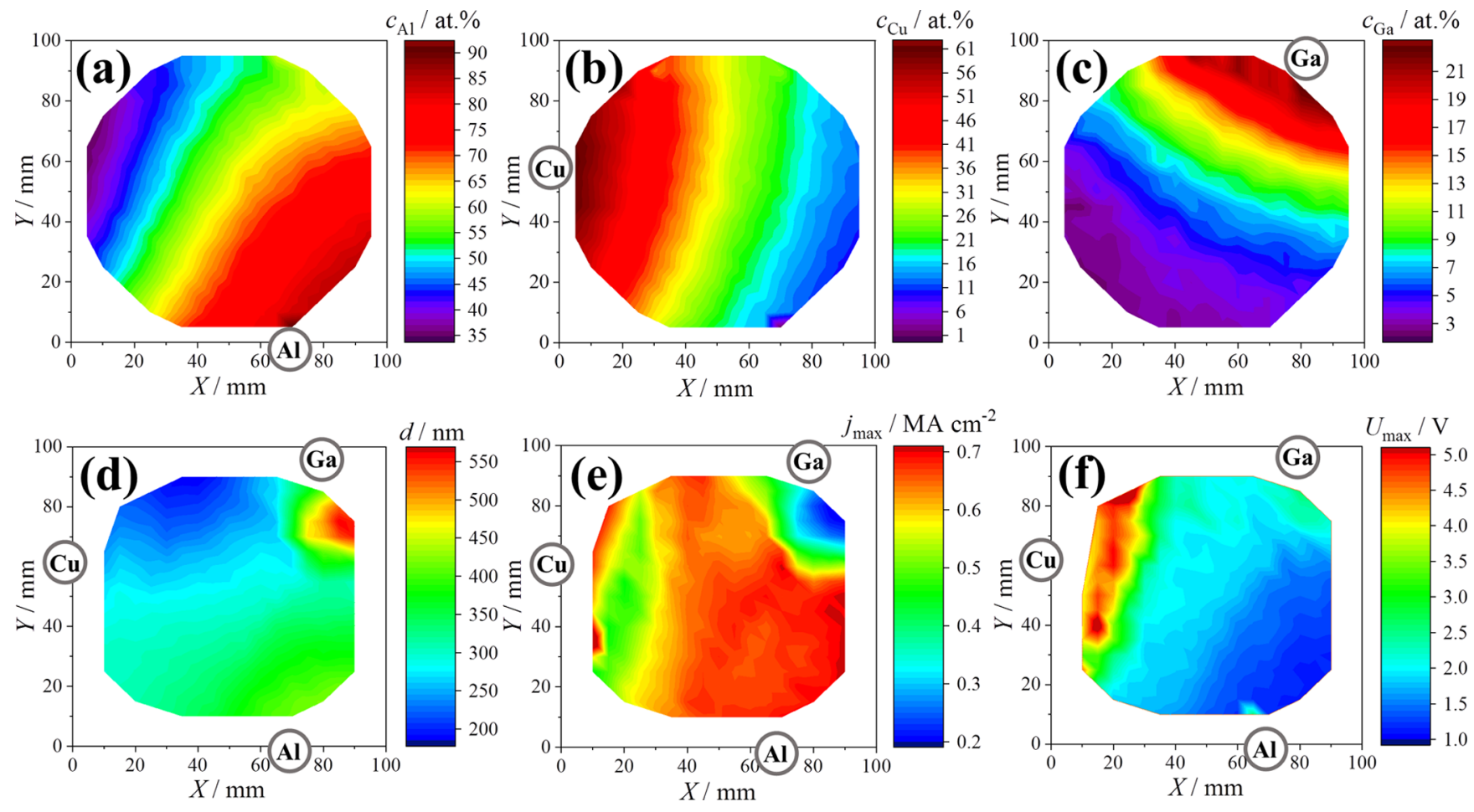

Figure 4. $\mathrm{Al}-\mathrm{Cu}-\mathrm{Ga}$ thin film library mappings (with indication of source positions): (a-c) composition, (d) film thickness, (e) maximum current density, and (f) maximum voltage.

same alloy concentration of $\mathrm{Al}-8$ at. $\% \mathrm{Ga}$, but $j_{\max }$ measured is smaller, falling well below $1 \mathrm{MA} \mathrm{cm}^{-2}$ closer to the evaporation sources.

The reason for this behavior may be found in the thickness mapping previously discussed. The increase of $j_{\max }$ with decreasing film thickness for the same composition can be linked with a transition from $3 \mathrm{D}$ to $2 \mathrm{D}$ effects valid for the selected test wire design (Figure $2 b, c$ ). It may be inferred that only below approximately $250 \mathrm{~nm}$, the thin film Al-8 at. \% Ga behaves as a bidimensional entity. In such case, there are only surface effects to be considered when discussing electromigration at nanoscale. As opposite to this, above $250 \mathrm{~nm}$, the films are thick enough for additional volume effects to settle in. Multiple slip planes in the depth of the film may accelerate the atomic movement in the electron flux direction resulting in a premature electrical failure. In any case, the dependence of $\mathrm{Al}-$ Ga thin film electrical performance on its thickness is a clear fact that needs to be acknowledged for further implementations in real life applications. Overall, according to our observations, when deposited on $\mathrm{SiO}_{2}$ substrates, $\mathrm{Al}-8$ at. \% $\mathrm{Ga}$ remains more susceptible to electromigration as compared to pure Al.

Mapping of the maximum voltage $U_{\max }$ at the moment of wire failure across the $\mathrm{Al}-\mathrm{Ga}$ library allows to indirectly visualize the alloy conductivity. This mapping is presented in Figure $2 \mathrm{~d}$. An increase in the maximum voltage may be interpreted as a decrease in conductivity, as directly suggested by the shape of $j-U$ curves previously discussed in Figure S2. Typically, after the Joule effect occurs, the current density almost goes into a plateau while $U$ increases. The highest conductivity in the Al-Ga alloys may be suggested close to the $\mathrm{Al}$ source likely due to the direct influence of $\mathrm{Al}$ conductivity which is higher when compared to Ga. However, the lowest $\mathrm{Al}-\mathrm{Ga}$ conductivity is not found in the vicinity of the $\mathrm{Ga}$ source but further away from it along the compositional gradient. This may again be related to the thickness profile of the library, when thinner films will result in decreased conductivities by increased wire resistances. In addition, combining Figure $2 \mathrm{c}, \mathrm{d}$, one can estimate the maximum power density that the $\mathrm{Al}-\mathrm{Ga}$ wire can withstand before electromigration failure.

In a similar manner to the one used for $\mathrm{Al}-\mathrm{Ga}$, the properties of $\mathrm{Cu}-\mathrm{Ga}$ test wire alloys were mapped, and the obtained results are shown in Figure 3. In part (a) of the figure, the compositional mapping is presented as provided by scanning EDX. The positions of the deposition sources are hinted as $\mathrm{Ga}$ on the left side and $\mathrm{Cu}$ on the right. With $\mathrm{Ga}$ concentration approximately ranging from 2 to 29 at. \%, a total compositional spread of 27 at. \% is concluded. Similar to the $\mathrm{Al}-\mathrm{Ga}$ case, this spread safely allows for compositional precisions of \pm 0.5 at. \% when selecting one particular $\mathrm{Cu}-$ Ga alloy.

The mapping of $\mathrm{Cu}-\mathrm{Ga}$ library thickness is presented in Figure $3 \mathrm{~b}$. When mixing $\mathrm{Cu}$ with $\mathrm{Ga}$, only one strong thickness gradient may be immediately observed, with the thickest films (above $500 \mathrm{~nm}$ ) in the vicinity of the $\mathrm{Cu}$ deposition source. On the left side of the mapping close to the Ga source, the library thickness raises slightly above $200 \mathrm{~nm}$. The thinnest films across the $\mathrm{Cu}-\mathrm{Ga}$ library are found diagonally opposite to the $\mathrm{Cu}$ source with values below $150 \mathrm{~nm}$. Similar to the previous library, the $\mathrm{Cu}-\mathrm{Ga}$ compositional spread thickness in the middle of the wafer is in the range of $350 \mathrm{~nm}$. The upperleft side of the thickness mapping shows a thickness decrease below $250 \mathrm{~nm}$, a threshold which was previously identified as 3D-2D transition for $\mathrm{Al}-\mathrm{Ga}$ films.

For concluding if this fact remains valid for the $\mathrm{Cu}-\mathrm{Ga}$ library, the $j_{\max }$ mapping presented in Figure $3 \mathrm{c}$ needs to be analyzed. More than half of the entire $\mathrm{Cu}-\mathrm{Ga}$ library surface 
indicates alloys with a maximum current density below $1 \mathrm{MA}$ $\mathrm{cm}^{-2}$, independent on their thicknesses. The smallest $j_{\max }$ value is found around $0.5 \mathrm{MA} \mathrm{cm}{ }^{-2}$ in the lower part of the mapping, while the highest is observed at the top. Here, a rather narrow region on the $\mathrm{Cu}-\mathrm{Ga}$ library reaches $j_{\max }$ values in an excess of 1.6 $\mathrm{MA} \mathrm{cm}^{-2}$, while the value measured on pure $\mathrm{Cu}$ test wires remains slightly below $1.2 \mathrm{MA} \mathrm{cm}^{-2} .51$ This increase of the ability to withstand electromigration can again be linked to the same $2 \mathrm{D}$ transition threshold discussed before for alloys with thickness below $250 \mathrm{~nm}$. Screening the $j_{\max }$ mapping resulted in identification of $\mathrm{Cu}-5$ at. \% Ga that is more resistant to electromigration effects when its thickness remains below 250 $\mathrm{nm}$. Similar to the previous case of the $\mathrm{Al}-\mathrm{Ga}$ library, when increasing the thickness of this selected alloy by moving vertically down across the $\mathrm{Cu}-\mathrm{Ga}$ library, the $j_{\max }$ value for thicker $\mathrm{Cu}-5$ at. \% Ga alloys decreases as well. Consequently, this alloy is identified as a possible replacement for pure $\mathrm{Cu}$ conducting lines in thin and ultrathin film high current applications.

Figure $3 \mathrm{~d}$ shows the $U_{\max }$ mapping of the entire $\mathrm{Cu}-\mathrm{Ga}$ thin film library. Close to the $\mathrm{Cu}$ evaporation source (on the right side), values slightly above $1 \mathrm{~V}$ indicate good electrical conductors. This is to be expected when comparing the one order of magnitude higher electrical conductivity of pure $\mathrm{Cu}$ with the conductivity of pure Ga. The values of $U_{\max }$ generally increase with the $\mathrm{Ga}$ amount, reaching values above $3.5 \mathrm{~V}$ for the highest Ga concentrations. A region that does not follow any of the previously observed trends may be identified at the bottom of the $U_{\max }$ mapping where the values remain very high independent on thickness or composition variations. However, in this zone, the library thickness remains above $250 \mathrm{~nm}$, thus $3 \mathrm{D}$ effects need to be considered. It is very common to encounter synergetic effects when screening thin film libraries, and this may be a good example of such a situation likely due to thickness changes. However, this compositional region of the $\mathrm{Cu}-\mathrm{Ga}$ library does not present too much interest from the point of view of ability to withstand electromigration as indicated by the current density mapping. The Ga concentrations remain above 10 at. \% for the entire lower part of the wafer, which is most likely too much for a good conducting alloy with high endurance under electrical current stress.

In order to complete the entire series of screening for possible alloys to be used in future electronic applications based on $\mathrm{Al}$ and $\mathrm{Cu}$ mixed with a liquid metal, the ternary $\mathrm{Al}-$ $\mathrm{Cu}-\mathrm{Ga}$ was also fully analyzed and mapped in a similar manner to the presented binaries. The results are summarized in Figure 4. Due to mixing three elements, the compositional mapping is now split in three color-coded images corresponding to each element presented in Figure $4 a-c$. The positions of each deposition source are immediately observable, matching the configuration presented in Figure 1a. Across the library, the $\mathrm{Al}$ concentration varied between 35 and 90 at. $\%, \mathrm{Cu}$ varied between 1 and 61 at. \%, while Ga amount changed between 3 and 22 at. \%. Even though the composition spread of Ga falls below the ranges obtained in the binary libraries, requirements for applying the proposed compositional precision of \pm 0.5 at. $\%$ are still met.

Thin film thickness mapping across the surface of the Al$\mathrm{Cu}-\mathrm{Ga}$ library was performed as before, and the results are shown in Figure 4d. The influence of each deposition source on the thickness variation is easily observable. The strongest influence is attributed to the Ga source in this case, test wire thicknesses reaching $550 \mathrm{~nm}$ being measured in the vicinity of the source. The second strongest influence on the film thickness is attributed to the $\mathrm{Al}$ source. Close to it in the lowerright corner of the mapping, values above $400 \mathrm{~nm}$ are observable. The weakest influence on the total thickness profile in the $\mathrm{Al}-\mathrm{Cu}-\mathrm{Ga}$ system is attributed to the $\mathrm{Cu}$ source. In its vicinity, the test wires showed thicknesses slightly above the $2 \mathrm{D}$ threshold of $250 \mathrm{~nm}$. However, the thinnest films were obtained at a location slightly away from the $\mathrm{Cu}$ source position toward the top of the wafer, where the film thickness dropped below $200 \mathrm{~nm}$. The behavior of the thickness profile is based on a complex vapor phase interaction between all three species, combined with surface adsorption/desorption phenomena during film formation. Test wires that may be considered bidimensional cover almost one-third of the entire library between $\mathrm{Cu}$ and $\mathrm{Ga}$ sources.

The ability to withstand electromigration was also tested in the ternary library, and the resulting mapping is provided in Figure $4 \mathrm{e}$. Most of the ternary alloys studied here showed $j_{\max }$ values ranging between 0.6 and $0.7 \mathrm{MA} \mathrm{cm}^{-2}$, thus behaving poorer as compared to both $\mathrm{Al}$ and $\mathrm{Cu}$ test wires. An increase in the electromigration effects is observed directly close to the Ga source, matching the same trend previously observed in both $\mathrm{Al}-\mathrm{Ga}$ and $\mathrm{Cu}-\mathrm{Ga}$ binary libraries. Additionally, on the left side of the wafer, a compositional region may be observed where electromigration effects are again stronger and $j_{\max }$ decreases toward $0.4 \mathrm{MA} \mathrm{cm}{ }^{-2}$. Here, the amount of $\mathrm{Ga}$ in the library ranges between 3 and 8 at. \%, a compositional range that proved to have a positive influence toward increasing the ability to withstand electromigration in the binary libraries. Unfortunately, in this region of the ternary library, the thickness of the wires remained mainly above the 2D threshold, possibly affecting the electromigration effects. Even if no ternary alloy with improved ability to withstand electromigration may be clearly identified in this study, a positive $\mathrm{Ga}$ influence can be concluded based on all libraries investigated.

Mapping of the maximum voltage across the ternary $\mathrm{Al}-$ $\mathrm{Cu}-\mathrm{Ga}$ is provided in Figure 4f. Mixing all three elements resulted in a larger $U_{\max }$ span (as compared to the binary libraries) between 1 and $5 \mathrm{~V}$. The lowest $U_{\max }$ indicating the highest conductivity is found in the vicinity of the $\mathrm{Al}$ source. The ternary alloys with the highest $U_{\max }$ are suggested for the lowest amount of $\mathrm{Al}$ below 40 at. \% in the library. Interestingly, here, the amount of $\mathrm{Cu}$ is above 45 at. \% but Ga concentration is also high reaching up to 15 at. \%. However, few alloys at the left edge of the wafer show high values for both maximum current densities and voltages. On this edge, an impressive maximum power density (before electrical failure) close to 3.5 MW $\mathrm{cm}^{-2}$ can be easily calculated. This may suggest that such ternary alloys can be considered for applications requiring high power densities rather than high currents, such as thin film heating elements.

XRD measurements were performed on all three thin film libraries. Supporting Information Figure S3 presents the diffractograms for the binaries $\mathrm{Al}-\mathrm{Ga}$ and $\mathrm{Cu}-\mathrm{Ga}$ together with the patterns from the database of the constituent metals. For both systems, the only diffraction peaks detected belong to $\mathrm{Al}$ and $\mathrm{Cu}$, respectively, both having a fcc structure. As the $\mathrm{Ga}$ content increases, there is a shift of the peaks toward lower $2 \theta$ angles caused by the formation of substitutional $\mathrm{Al}-\mathrm{Ga}$ and $\mathrm{Cu}-\mathrm{Ga}$ solid solutions. The shift (clearly observable for the (111) peak) is more pronounced in the $\mathrm{Cu}-\mathrm{Ga}$ system because the size of the replacing atom ( $187 \mathrm{ppm}$ for $\mathrm{Ga}$ ) is 
much larger than the size of $\mathrm{Cu}(128 \mathrm{ppm})$ but not of $\mathrm{Al}$ (143 $\mathrm{ppm}$ ). Due to the low temperature deposition method, solid solutions form in the film, in spite of the low solubility of Ga in $\mathrm{Al}$ only up to 9 at. $\%$ and in $\mathrm{Cu}$ up to approximately 21 at. $\% .^{53,54}$

Figure S4 presents the diffractograms acquired on the ternary library. From the comparisons along the change of $\mathrm{Ga}$ concentration (Figure $\mathrm{S} 4 \mathrm{a}-\mathrm{c}$ ), it is evident that the main intermetallic phases are $\mathrm{CuAl}_{2}$ and $\mathrm{CuAl}$, which are present together with pure $\mathrm{Al}$ for the $\mathrm{Al}$-rich areas. For a better visualization of $\mathrm{Ga}$ influence onto the phase formation, independent graphs were analyzed for constant $\mathrm{Cu}$ concentrations but with variable $\mathrm{Al}$ and $\mathrm{Ga}$ contents (Figure S4d-f) and for constant $\mathrm{Al}$ concentrations but with variable $\mathrm{Cu}$ and $\mathrm{Ga}$ contents (Figure $\mathrm{S} 4 \mathrm{~g}-\mathrm{i}$ ). Additionally, the intermetallic patterns containing $\mathrm{Cu}$ and $\mathrm{Ga}$ were also plotted $\left(\mathrm{CuGa}_{2}\right.$, $\mathrm{Cu}_{3} \mathrm{Ga}$, and $\mathrm{Cu}_{9} \mathrm{Ga}_{4}$ ) both in Figures $\mathrm{S} 3$ and $\mathrm{S} 4 \mathrm{~d}-\mathrm{f}$, while Figure $\mathrm{S} 4 \mathrm{j}$ provides the location and nomenclature information for the XRD measurement spots. As indicated by the $\mathrm{Al}-\mathrm{Ga}$ phase diagram, no $\mathrm{Al}-\mathrm{Ga}$ intermetallic phases exist. ${ }^{33}$ The appearance, disappearance, and change from one $\mathrm{Al}-\mathrm{Cu}$ intermetallic compound to another compound are related to the ratio of main elements, respectively $\mathrm{Cu}$ and $\mathrm{Al}^{55}$ No intermetallic phases containing $\mathrm{Ga}$ were found, not even for regions where the $\mathrm{Ga}$ concentration was relatively high $(>10$ at. \%). For example, for a concentration of $\mathrm{Cu}$ of approximately 17 at. \%, the phase found was $\mathrm{CuAl}_{2}$ and $\mathrm{Al}$ peaks also emerged for $\mathrm{Al}$ concentrations above 70 at. \%. For approximately 36 at. \% $\mathrm{Cu}$, independent of $\mathrm{Al}$ (and $\mathrm{Ga}$ content), only a mixture of $\mathrm{CuAl}$ and $\mathrm{CuAl}_{2}$ was identified, whereas for regions with approximately 51 at. $\% \mathrm{Cu}$, mainly the $\mathrm{CuAl}$ intermetallic was found, similar to the patterns for regions with 45 at. \% $\mathrm{Al}$. For these areas, the Ga content was up to 10 at. \%. Similarly, for regions with $\mathrm{Al}$ contents higher than 45 at. \%, independent of $\mathrm{Ga}$ concentration, only $\mathrm{CuAl}$ and $\mathrm{CuAl}_{2}$ were identified.

Upon Joule heating, it is expected that structural changes occur inside the alloys. The literature reports on the precipitation of intermetallic $\mathrm{Cu}-\mathrm{Ga}$ phases even at room temperature, when liquid $\mathrm{Ga}$ is brought into contact with a $\mathrm{Cu}$ plate. With additional heating up to $200{ }^{\circ} \mathrm{C}$, the formed $\mathrm{CuGa}_{2}$ intermetallic was found to be very stable, and its properties (lower hardness and Young's modulus as compared to $\mathrm{Cu}-\mathrm{Sn}$ alloys) make it extremely attractive for interconnects. ${ }^{56}$ In a similar study, where the $\mathrm{Ga} / \mathrm{Cu}$ system was allowed to react for a long time, above approximately $260{ }^{\circ} \mathrm{C}$, a very thin $\mathrm{Cu}_{9} \mathrm{Ga}_{4}$ intermetallic was also found, which was formed by the decomposition of $\mathrm{CuGa}_{2} .{ }^{57,58}$

In consonance with the binary phase diagram, in the case of the $\mathrm{Al}-\mathrm{Ga}$ system, upon heating and subsequent cooling, because no intermetallic phases form, the most probable outcome is phase/material segregation. In the case of the binary $\mathrm{Cu}-\mathrm{Ga}$ system, upon Joule heating, it can be expected that intermetallic phases form. For the $\mathrm{Al}-\mathrm{Cu}-\mathrm{Ga}$ library, $\mathrm{Al}-$ $\mathrm{Cu}$ intermetallic phases are already present immediately after the deposition; therefore, it can be concluded that as a function of composition, some mixed intermetallics containing $\mathrm{Al}-\mathrm{Cu}-$ $\mathrm{Ga}$ or $\mathrm{Al}-\mathrm{Cu}$ and $\mathrm{Ga}$ segregation might occur during testing. In the current study, test wires were deliberately exposed to extreme current densities until a mechanical failure occurred. From the SEM examination, in many cases, it seemed that the material was melted at the region of failure. Consequently, the influence of the intermetallic phases on the failure mechanism is difficult to be accurately assessed postfailure because of the present design of experiments imposed by the objective of the study.

An approach to make some predictions based on the intermetallic phase that might develop during Joule heating is to overlap the compositional maps with current density maps in Figures 2-4 and simultaneously to analyze the phase diagrams and diffractograms. For both binaries, the values for $j_{\max }$ are found up to a Ga maximum concentration of 15 at. \%. For alloys with higher Ga content, the failure occurs at lower current densities. Since for the $\mathrm{Al}-\mathrm{Ga}$ system no intermetallics are present, it could be expected that at this Ga concentration, its segregation and wetting of the polycrystalline $\mathrm{Al}$ film grain boundaries take place, suppressing electromigration effects. $^{33-37}$ When the Ga content is higher though, the Ga exodus from the $\mathrm{Al}$ matrix and accumulation at grain boundaries upon heating might be excessive and detrimental, leading to a mechanically unstable structure due to grain "sliding" and eventual continuous film dewetting. In the case of the $\mathrm{Cu}-\mathrm{Ga}$ system, a $\mathrm{Ga}$ content to 17 at. \% is soluble in $\mathrm{Cu}$ according to the phase diagram at room temperature and up to $1000{ }^{\circ} \mathrm{C}$. For these alloys, upon heating and cooling, most probably no or a very limited volume of intermetallics form. For higher concentrations of $\mathrm{Ga}$, the precipitation of intermetallic phases might occur, phases which upon cooling might experience phase transformations from high temperature to room temperature crystal structures. Formation of intermetallic phases and crystalline structure transformations lead to material embrittlement, which in turn may affect detrimentally the resistance to electromigration. ${ }^{48}$ For the ternary $\mathrm{Al}-\mathrm{Cu}-\mathrm{Ga}$ system, the highest current density is found in a broad concentration range of $\mathrm{Cu}$, up to 31 at. \%, and $\mathrm{Al}$ content higher than 50 at. \%, whereas $\mathrm{Ga}$ seems not to have a dramatical effect. Analyzing the XRD patterns, within these compositional ranges, a mixture of the $\mathrm{CuAl}_{2}$ and $\mathrm{CuAl}$ intermetallics is already present in the as-deposited samples, with $\mathrm{CuAl}_{2}$ being the predominant phase. For higher $\mathrm{Cu}$ contents, where the failure occurs at lower $j_{\max }$ the main phase is $\mathrm{CuAl}$. Upon heating above $\approx 560{ }^{\circ} \mathrm{C}$ (which might occur during the Joule heating of the wires), a change in the crystalline structure occurs that might lead to mechanical damage of the wire, embrittlement, and eventually early failure.

Compared to previously studied $\mathrm{Al}-\mathrm{Cu}$ alloys, ${ }^{32}$ using $\mathrm{Ga}$ as an alloying element for either $\mathrm{Al}$ or $\mathrm{Cu}$ improved the electromigration resistance of test wires. Studying $\mathrm{Al}-\mathrm{Cu}$ thin film libraries, maximum current density $\left(j_{\max }\right)$ values up to $0.9 \mathrm{MA} \mathrm{cm}^{-2}$ were found on similar test wire designs. ${ }^{32}$ In the present work, both $\mathrm{Al}-\mathrm{Ga}$ and $\mathrm{Cu}-\mathrm{Ga}$ have showed better performances with $j_{\max }$ values above 1 and $1.5 \mathrm{MA} \mathrm{cm}{ }^{-2}$, respectively. However, the values obtained from the $\mathrm{Al}-\mathrm{Cu}-$ Ga ternary library screening reached only a maximum of 0.7 $\mathrm{MA} \mathrm{cm} \mathrm{cm}^{-2}$.

Electromigration in Selected Gallium Alloys on Flexible Polymer Substrates. Following the screening of $\mathrm{Al}-\mathrm{Ga}$ and $\mathrm{Cu}-\mathrm{Ga}$ thin film combinatorial libraries on $\mathrm{SiO}_{2}$, the most promising alloys ( $\mathrm{Al}-8$ at. $\% \mathrm{Ga}$ and $\mathrm{Cu}-5$ at. $\% \mathrm{Ga}$ ) were deposited on PEN substrates for testing their electromigration behavior in flexible electronics. No ternary alloy was selected in this study mainly due to their low $j_{\max }$ values as compared to pure $\mathrm{Al}$ or $\mathrm{Cu}$. The surface microstructure of these alloys was compared to the microstructure of $\mathrm{Al}$ and $\mathrm{Cu}$, and the results are presented in Figure S5. Both $\mathrm{Al}$ and $\mathrm{Cu}$ microstructures on $\mathrm{SiO}_{2}$ are well researched in the literature, 

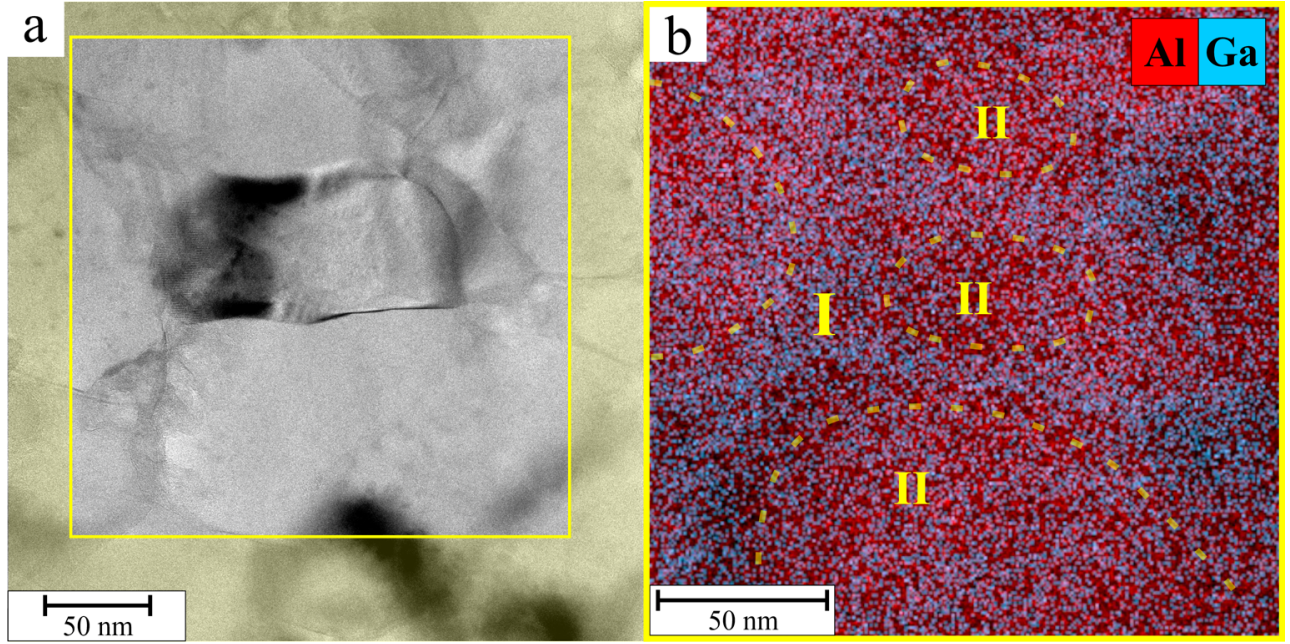

Figure 5. BF TEM top-view image of the as-deposited $\mathrm{Al}-8$ at. \% Ga sample on the PEN substrate (a) along with the general corresponding element distribution map of the selected area (b).
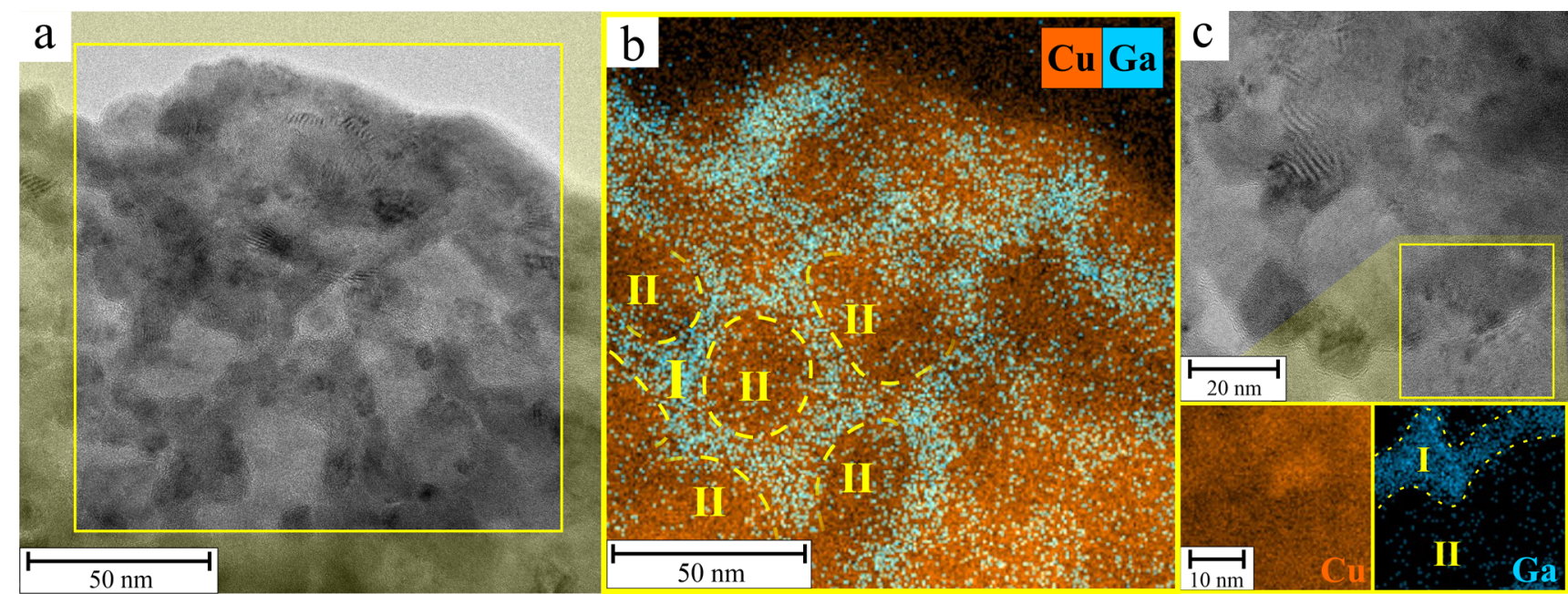

Figure 6. BF TEM top-view image of the as-deposited $\mathrm{Cu}-5$ at. \% Ga sample on the PEN substrate (a), corresponding element distribution map of the selected area (b), and HR TEM image with element distribution maps (c).

nowadays being considered as common knowledge in thin film communities. As expected, when thermally evaporated on $\mathrm{SiO}_{2}$, both $\mathrm{Al}$ and $\mathrm{Cu}$ films show a fine grain structure in the $100 \mathrm{~nm}$ range, and the $\mathrm{Al}$ one also contains secondary larger grains protruding from the surface. Addition of Ga changes these microstructures. In case of the $\mathrm{Al}$ alloy, $\mathrm{Ga}$ leads to formation of a rougher surface and a complete disappearing of the secondary larger grains, while $\mathrm{Ga}$ alloyed with $\mathrm{Cu}$ leads to a smoother surface decorated with slightly larger secondary grains. When deposited on PEN, both $\mathrm{Al}-8$ at. \% Ga and $\mathrm{Cu}-5$ at. \% Ga thin film formation is affected by the much lower surface energy of the polymer as compared to the $\mathrm{SiO}_{2}$. As a result, very smooth surfaces are observed in both cases in Figure S5; the $\mathrm{Cu}$ alloy additionally shows secondary grains with a size of approximately $1 \mu \mathrm{m}$. Also, the fine scratches common to the PEN surface are reproduced in the metallic alloy microstructure confirming previous observations on pure $\mathrm{Al}^{59}$

In order to observe the influence of $\mathrm{Ga}$ at atomic scale, TEM was performed on both selected Ga alloys. In Figure 5 a brightfield (BF) TEM image obtained on the surface of Al-8 at. \% Ga is presented. Several grains are observable in part (a) of the figure with distinct grain boundaries. Compositional analysis mapping of the selected region fulfilled via EDX is presented in part (b) of the figure as a color-coded image. Even though Ga atoms are distributed over the entire analyzed area, slight $\mathrm{Ga}$ enrichment is observed predominantly at grain boundaries. The boundary regions (marked in the figure with I) contain most of the Ga present in the TEM specimen, while the Ga amount within the metallic grains (marked with II) decreases, values around $2.5 \pm 1$ at. \% being obtained from quantitative analysis. This spatial distribution of $\mathrm{Ga}$ matches the previous conclusion regarding nonexistent $\mathrm{Al}-\mathrm{Ga}$ intermetallics. During co-deposition, $\mathrm{Al}$ and $\mathrm{Ga}$ atoms condense together on the PEN surface, and during film growth, grain development leads to a weak accumulation of $\mathrm{Ga}$ in grain boundaries even at low (room) temperatures. This accumulation may be responsible for the noted increase in electromigration resistance since the presence of Ga may inhibit the continuous grain growth under high electron fluxes, as previously imaged in pure $\mathrm{Al} \mathrm{films.}{ }^{32}$

In a similar manner, the $\mathrm{Cu}-5$ at. \% Ga thin film deposited on PEN was imaged via TEM, and the results are summarized in Figure 6. In part (a), a BF image is provided where grains and grain boundaries are visible. The area selected is color- 


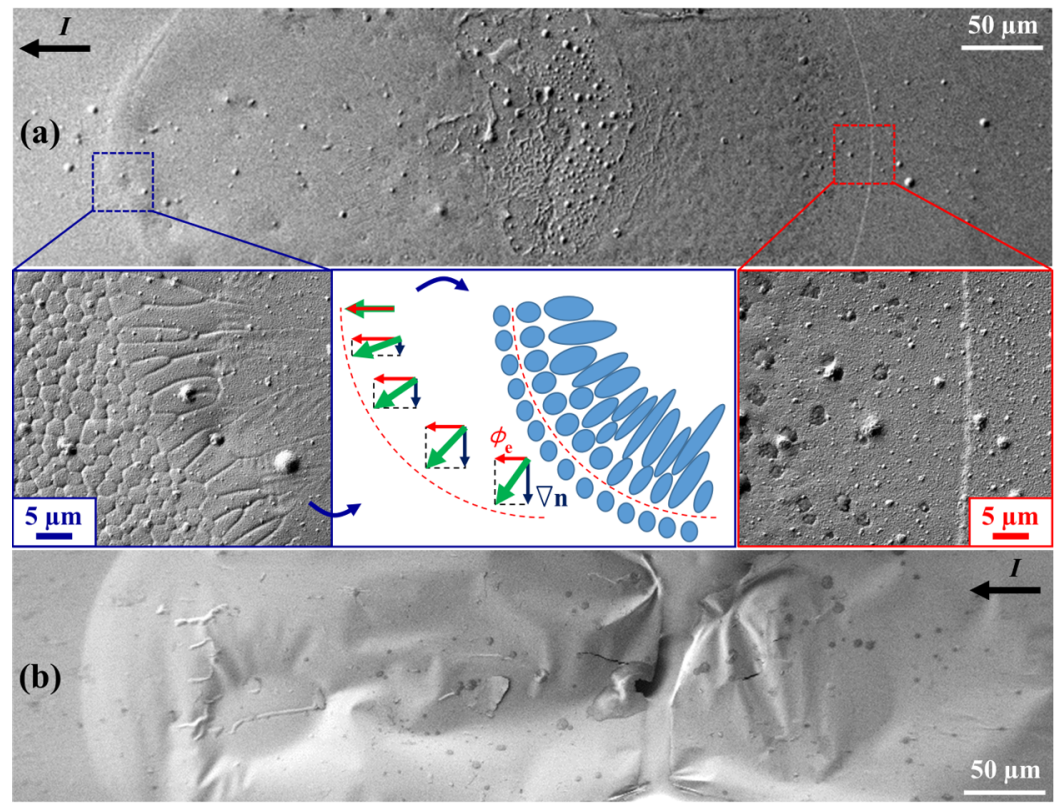

Figure 7. Damaged regions after electromigration testing of Al-8 at. \% Ga (a) on $\mathrm{SiO}_{2}$ with model for grain evolution and (b) on PEN substrates.

coded compositionally mapped by EDX for localizing Ga on the surface. As observed in part (b) of the figure, Ga segregates in the grain boundaries (regions I), and very small amounts may be hinted within metallic grains (regions II). Also in this case, the absence of intermetallics suggested by XRD studies is confirmed. Together with the Ga segregation at low (room) temperature, this likely is the reason for the observed enhancement in the electromigration resistance. HR TEM of the same specimen is presented in Figure $6 c$, and the selected area is compositionally mapped. Representative regions I and II are color-coded, and the presence of Ga mainly in the grain boundaries is evidenced. Quantitative analysis indicated that Ga concentration in region I locally reaches $11 \pm 1$ at. \% while in region II, it is negligible ( $<0.5$ at. \%). Identical to the case of the $\mathrm{Al}-\mathrm{Ga}$ alloy, the $\mathrm{Cu}$ and $\mathrm{Ga}$ surface distribution likely occurred during film nucleation and growth, with Ga effectively pinning down the $\mathrm{Cu}$ grains and thus inhibiting their electron flux-induced modifications during electromigration testing.

The microstructure changes induced by high electron fluxes in $\mathrm{Al}-8$ at. \% Ga were investigated by imaging the damaged areas of the test wires deposited on both $\mathrm{SiO}_{2}$ and PEN substrates. These details are together presented in Figure 7. The electron flow direction is from right to left as indicated in the figure. The test wire deposited on $\mathrm{SiO}_{2}$ shows the features typical to atomic displacement under high electron fluxes. ${ }^{21-25}$ In the central failure zone responsible for the final open circuit condition, the film completely migrated revealing the underlying substrate. Droplets of the molten material can be observed around the failure line, most likely as a result of the local temperature increase by the Joule effect. ${ }^{51}$ Both anodic (on the left side) and cathodic (on the right side) regions are clearly visible, each having its own damage front more accentuated toward the middle of the test line. The magnified image of the anodic damage front presents a snapshot into dynamics of the grain evolution occurring during the electromigration. On the right side of the image, very long grain boundaries are observable that further define elongated grain domains when approaching the damage front. Beyond the front line, almost round grain domains may be seen forming the remaining surface of the $\mathrm{Al}$ alloy. This behavior is schematically modeled in the center drawing of Figure 7.

The surface grain evolution is triggered by both the force associated to the electron flux $\Phi_{\mathrm{e}}$ (also termed "electron wind" force) and the force associated to the gradient of the atomic concentration $n$ perpendicular to the current flow direction. $^{21-23}$ The first force is stronger in the middle of the test line, where the electron density is higher and its intensity decreases as approaching the wire edges. Since electrons prefer the 'easiest' path (i.e. the middle of the wire), the wire edges will always show an increased local resistance due to boundary effects. In the direction perpendicular to the current flow, an atomic concentration gradient appears due to the higher number of dislodged atoms at the middle of the wire (under interaction with higher electron fluxes) as compared to the edges. The same behavior is observed during electromigration in pure $\mathrm{Al}^{32}$ The combined influence of these two forces changes the growth direction of the grain boundaries as schematically described in Figure 7. However, unlike the case of pure $\mathrm{Al}$, the presence of $\mathrm{Ga}$ triggers a fragmentation of the grain boundaries leading to the currently modeled grain behavior. The segregation of $\mathrm{Ga}$ in the grain boundaries is likely linked to the formation of elongated domains along the damage front in the current flow direction. ${ }^{34-37}$ This may inhibit the overall mobility of the grain boundaries leading to enhanced ability to withstand electromigration.

The atomic displacement in the direction of electron flow leads to hillocks and consequent void formation. ${ }^{21-25}$ Usually, hillocks are better observable on the anodic side while void formation can be found in the magnified cathodic front image presented in Figure 7a. The front line is clearly visible, and a thickness change is also apparent due to atomic movement toward the anodic side. When changing the substrate from $\mathrm{SiO}_{2}$ to PEN, the electromigration behavior of $\mathrm{Al}-8$ at. \% Ga thin film alloy test wire also changes. Both anodic and cathodic damage fronts are not directly visible anymore as indicated in Figure $7 \mathrm{~b}$. Here, only the central failure zone is visible, and no special surface morphology was observed when analyzing the wire after electrical testing. Additionally, on PEN, the Al alloy 
film delaminates during electromigration and film buckling and wrinkling may be observed in the figure. Because the film adhesion is poorer on $\mathrm{PEN}$ as compared to $\mathrm{SiO}_{2}$, the delamination is likely created by the increase in the Joule heating temperature. Once the film starts to lose its adhesion to the substrate, a new surface is created that was originally pinned by the substrate. Consequently, that allows for a localized atomic rearrangement in the vicinity of the failure zone, leading to the disappearance of anodic and cathodic damage fronts. Additionally, because the temperature increase may be in an excess of $800 \mathrm{~K}$, delamination of the alloy film prevents thermal destruction of the PEN by allowing a faster cooling of the metallic surface. ${ }^{51}$ Since grain changes characteristic to electromigration (arrow head, elongated grains, voids and hillocks) are observable in the tested wires, significant thermal effects are likely very localized in the breakdown region.

The microstructure changes during electromigration in $\mathrm{Cu}-5$ at. \% Ga were also investigated as a function of the substrate. In Figure 8, images of the test wires deposited on $\mathrm{SiO}_{2}$ and

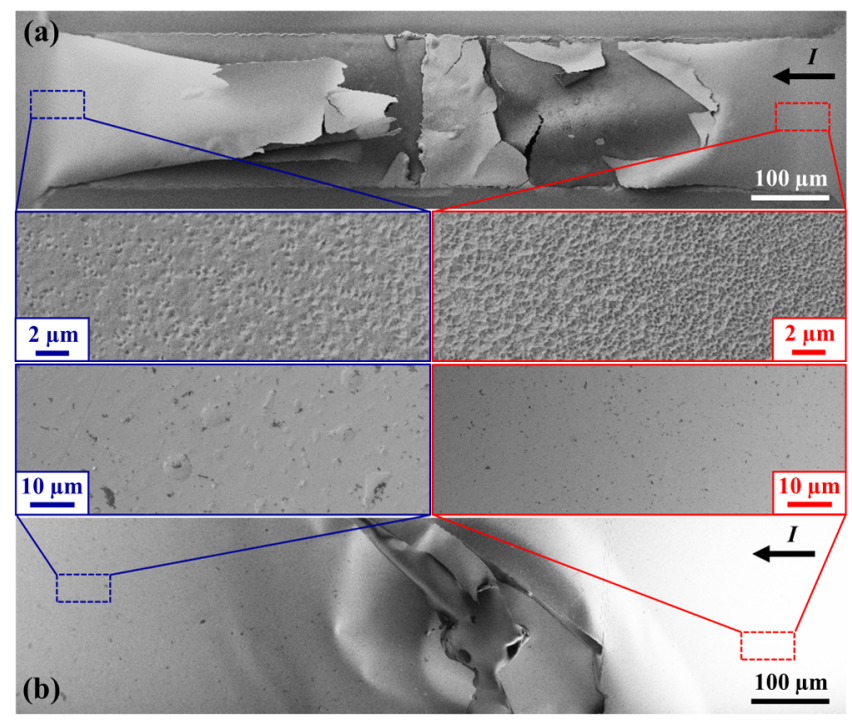

Figure 8. Damaged regions after electromigration testing of $\mathrm{Cu}-5$ at. $\% \mathrm{Ga}(\mathrm{a})$ on $\mathrm{SiO}_{2}$ and (b) on PEN substrates.

PEN substrates are provided. In the case of the selected $\mathrm{Cu}$ alloy, the use of both substrates led to very aggressive film failures. Electromigration is accompanied in both cases by strong film delamination. If delamination on PEN may be understood from the point of view of poorer film adhesion, as discussed previously for the $\mathrm{Al}$ alloy, the delamination on $\mathrm{SiO}_{2}$ may be attributed to stresses built up during film formation in the vacuum phase. The stress is released in the electrical failure moment when the wire completely explodes from the surface. Similar to the $\mathrm{Al}$ alloy case, the film delamination prevents a good observation of anodic and cathodic damage fronts. During electromigration tests on pure $\mathrm{Cu}$ on $\mathrm{SiO}_{2}$, these fronts were poorly observable even in the absence of delamination. ${ }^{51}$ The more aggressive failure of the $\mathrm{Cu}-5$ at. \% Ga can be attributed to the $\mathrm{Ga}$ addition to $\mathrm{Cu}$ leading to grain boundary wetting and faster deterioration of mechanical properties.

Magnified images of anodic and cathodic regions presented in Figure 8a for $\mathrm{Cu}-5$ at. \% Ga wires show rather similar surface structures. A mixture of voids and hillocks of varying densities is observable on both sides. Denser microstructure features are present on the cathodic side with sizes constantly increasing toward the failure zone. The influence of $\mathrm{Ga}$ is suggested in both anodic and cathodic regions by a lack of grain structuring, when compared to behavior of pure $\mathrm{Cu}^{51}$ When tested on PEN substrates, $\mathrm{Cu}-5$ at. \% Ga shows even less surface features. A high number of hillocks with a size of approximately $10 \mu \mathrm{m}$ may be observed in the anodic region in the magnified parts of Figure $8 \mathrm{~b}$. Additionally, sub- $\mu \mathrm{m}$ darker spots/grains are visible on both sides randomly distributed on the surface.

Apart from withstanding tremendous current densities when deposited on PEN, the $\mathrm{Al}$ and $\mathrm{Cu}$ alloys selected by screening the libraries should be mechanically stable enough for being suitable for flexible electronics circuitry. Since it was shown that stress build-up plays a role in the wire failure during electrical testing, the wire behavior during additional mechanical stress should be investigated. In order to assess this aspect, a simple bending test was performed before electromigration testing. However, the bending had a rather extreme nature since the PEN foil was bent $180^{\circ}$ in the middle of the test wire with a bending radius in the range of the PEN foil thickness. A schematic of the bending procedure is presented in Figure 9 together with details of the electromigration damage after bending on both $\mathrm{Al}-8$ at. \% Ga and $\mathrm{Cu}-$ 5 at. \% Ga test wires. Similar to the previous cases, the current flow direction is indicated in the figure to ease the identification of anodic and cathodic regions.

Observation of the electromigration behavior after performing the bending test of the $\mathrm{Al}$ alloy deposited on PEN (Figure 9a) reveals a microstructure similar to the one presented in Figure $7 \mathrm{~b}$. However, the presence of larger dark spots on the surface is evidenced here. Unfortunately, local chemical analysis of these spots by EDX/SEM was not possible due to the PEN that does not allow bombardment with electrons with energies in excess of $2 \mathrm{keV}$. The number of these large spots is higher in the anodic side, and they show circular symmetries suggesting molten droplets of the material. This is easily observable in the magnified image of the anodic zone. In part (b) of Figure 9, the $\mathrm{Cu}-5$ at. \% Ga wire is imaged after the bending procedure and electromigration testing. Here, periodic lines along the test wires may be observed that suggest a transversal delamination initiated probably during the bending procedure. Such delamination was not identified in the absence of supplemental mechanical stress, as shown in Figure $8 \mathrm{~b}$. In the magnified image of the anodic side, fine cracks are better visible and their mechanical nature may be concluded. Obviously, these cracks along the test wire will affect the electrical performance of the $\mathrm{Cu}$ alloy under extreme mechanical stress.

Even though the $\mathrm{Cu}$ alloy showed supplemental microstructural damage due to the bending procedure, in most reallife applications of flexible electronics, the substrates will not need such extreme bending. Mild mechanical movements, for example, such in the case of skin electronics, are the normal requirements. ${ }^{18}$ Such situation is illustrated as a proof of principle in Figure S6 together with an optical image of the PEN substrates immediately after test wire patterning by direct writing. A Cu-5 at. \% Ga row of wires is bent at different angles following the natural shape of a human finger. This may stress one test wire under angles in excess of $90^{\circ}$ but with very large bending radii in the $1 \mathrm{~cm}$ range.

A visual summary of the present study is given in Figure 10 where the $j-U$ curves measured on the selected $\mathrm{Al}$ and $\mathrm{Cu}$ alloys are compared to pure $\mathrm{Al}$ and $\mathrm{Cu}$ on different substrates. 


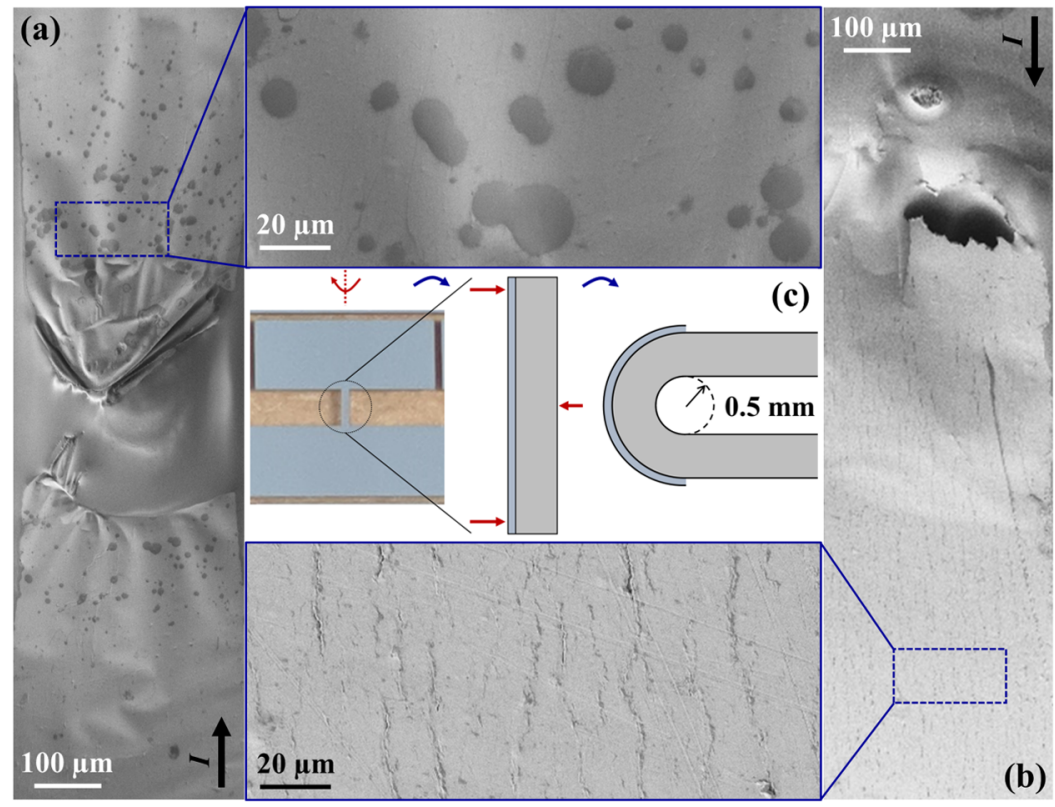

Figure 9. Damaged regions due to electromigration after mechanical bending of Al-8 at. \% Ga alloy (a) and Cu-5 at. \% Ga alloy (b) deposited on PEN substrates. (c) View and description of the bending geometry.
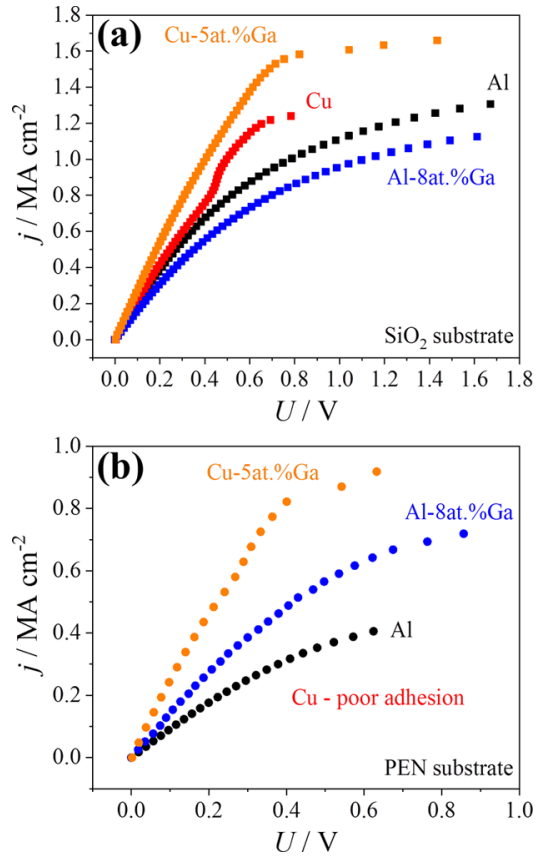

Figure 10. Electromigration testing on $2 \mathrm{D}$ wires made from various metals and Ga alloys on $\mathrm{SiO}_{2}$ (a) and PEN (b) substrates.

On the rigid $\mathrm{SiO}_{2}$ substrate, pure $\mathrm{Al}$ thin films are preferred against $\mathrm{Al}-8$ at. \% Ga due to the approximately $18 \%$ higher maximum current density able to be transported through $\mathrm{Al}$ wires before failure. However, when applied to flexible electronics (i.e. PEN substrates), the situation changes in favor of Al-8 at. \% Ga. Because the nature of the substrate is the only difference between the two cases, this approximate $47 \%$ increase in the maximum current density of the alloy on PEN must be mainly due to the notoriously poor adhesion of $\mathrm{Al}$ on polymers. If the thin film can easily delaminate from the substrate during the electromigration testing, the back side of the film becomes also an active surface for atomic migration, thus enhancing the overall effect in the test wire leading to premature damage. The importance of free surfaces in electromigration resistance was previously emphasized by using anodic oxides on top of the test wires. ${ }^{32}$ Adding Ga improves $\mathrm{Al}$ adhesion, by avoiding premature delamination and keeping (for longer time) only the top surface active for electromigration, thus increasing the maximum current density values for flexible electronic applications. As compared to the performance of the pure $\mathrm{Cu} 2 \mathrm{D}$ wire on $\mathrm{SiO}_{2}$, the identified $\mathrm{Al}$ 5 at. $\% \mathrm{Cu}$ is superior, having a maximum current density increased by approximately $25 \%$. This increase is related to the discussed grain boundary wetting with Ga presented in Figure $6 \mathrm{c}$. Since no adhesion promoters of any kind were applied in this study prior to thin film deposition on PEN, the pure $\mathrm{Cu}$ test wire on the polymer delaminated immediately after deposition. No electrical testing was possible on pure $\mathrm{Cu}$ due to its poor adhesion to the substrate, the film being removed directly in the lift-off phase of test wire patterning. However, addition of 5 at. \% Ga changed this situation. Not only that on PEN substrates the $\mathrm{Cu}$ alloy was more adherent but its electrical performance was superior to that of the $\mathrm{Al}-8$ at. \% Ga or of pure $\mathrm{Al}$ films.

\section{CONCLUSIONS}

This study offers access to electrical performances of a wide range of $\mathrm{Al}-\mathrm{Ga}, \mathrm{Cu}-\mathrm{Ga}$, and $\mathrm{Al}-\mathrm{Cu}-\mathrm{Ga}$ alloys for future use in electrical interconnects of electronic devices. This is achieved by screening binary and ternary thin film combinatorial libraries obtained by co-evaporation of $\mathrm{Al}, \mathrm{Cu}$, and $\mathrm{Ga}$ in vacuum on rigid $\mathrm{SiO}_{2}$ substrates. Lithographically patterning $2 \mathrm{D}$ test wires, combined with a personalized 4-point measurement head and LabVIEW automation, enabled electrical high throughput experimentation by applying current and measuring the potential drop across each test wire. Screening for alloys resistant against electromigration was performed by observing the maximum current density and voltage at the electrical failure moment for a given alloy. 
Two specific binary alloys (Al-8 at. \% Ga and $\mathrm{Cu}-5$ at. \% Ga) emerged as promising for future use. Throughout the entire study, Ga concentrations in the range of $3-8$ at. \% were identified as having a positive influence on improving the ability to withstand electromigration. Analysis of the surface morphology of the selected alloys after electromigration testing allowed modeling the processes occurring during atomic displacement. The grain boundary dynamics during electromigration is attributed to a resultant between the force corresponding to the electron flux density and the force corresponding to the atomic concentration gradient perpendicular to the current flow direction. Thickness profiles mapped across the entire surface of libraries indicated that for this combination of materials, a transition from $3 \mathrm{D}$ to $2 \mathrm{D}$ phenomena occurs for films thinner than $250 \mathrm{~nm}$. This reveals a prominent potential of using conducting lines with thicknesses below this limit for real-life applications. However, it is still vital to highlight the effect of size (or thickness in our case) on the observed materials' properties, which also could play a crucial role in achieving supreme performance. This research is in a frame of upcoming investigations.

Both $\mathrm{Al}$ and $\mathrm{Cu}$ alloys identified through the screening were deposited on PEN flexible substrates. Their electrical characteristics indicated that $\mathrm{Al}-8$ at. \% Ga is a better choice for conducting lines in flexible electronics as compared to pure Al. Moreover, $\mathrm{Cu}-5$ at. \% Ga showed superior properties as compared to pure $\mathrm{Cu}$ on both $\mathrm{SiO}_{2}$ and PEN substrates. The film adhesion to PEN is positively affected by alloying $\mathrm{Al}$ or $\mathrm{Cu}$ with Ga. After additional extreme mechanical stressing of test wires on PEN, the $\mathrm{Al}$ alloy behaved similarly to wires before stressing while the $\mathrm{Cu}$ alloy suffered a transversal delamination as compared to the nonstressed situation. Overall, for flexible electronic applications using PEN substrates, future devices may consider $\mathrm{Al}-8$ at. \% Ga and $\mathrm{Cu}-5$ at. \% Ga alloys for replacing pure $\mathrm{Al}$ due to their improved ability to withstand electromigration by almost $50 \%$ and more than $100 \%$, respectively.

\section{ASSOCIATED CONTENT}

\section{SI Supporting Information}

The Supporting Information is available free of charge at https://pubs.acs.org/doi/10.1021/acsami.0c22211.

Glass wafer with patterned 2D Al-Ga test wires and contact positions of the 4-point measurement head used for $j-U$ analysis during library mapping; selected $j-U$ curves along $\mathrm{Al}-\mathrm{Ga}$ gradient; XRD mapping of $\mathrm{Al}-\mathrm{Ga}$ and $\mathrm{Cu}-\mathrm{Ga}$ libraries; XRD mapping of the $\mathrm{Al}-\mathrm{Cu}-\mathrm{Ga}$ library; SEM images of pure metals and selected alloys on $\mathrm{SiO}_{2}$ and PEN substrates; and photograph of direct written test wires on PEN before metallization and simple bending of test wires-skin electronics proof of principles (PDF)

\section{AUTHOR INFORMATION}

\section{Corresponding Author}

Andrei Ionut Mardare - Institute of Chemical Technology of Inorganic Materials, Johannes Kepler University Linz, 4040 Linz, Austria; (1) orcid.org/0000-0003-4137-1994; Phone: +43 7322468 8702; Email: andrei.mardare@ jku.at; Fax: +43732 24688710

\section{Authors}

Saeedeh Ravandi - Institute of Chemical Technology of Inorganic Materials, Johannes Kepler University Linz, 4040 Linz, Austria

Alexey Minenkov - Christian Doppler Laboratory for Nanoscale Phase Transformations, Center of Surface and Nanoanalytics, Johannes Kepler University Linz, 4040 Linz, Austria; O orcid.org/0000-0002-6791-3344

Cezarina Cela Mardare - Institute of Chemical Technology of Inorganic Materials and Christian Doppler Laboratory for Combinatorial Oxide Chemistry at the Institute of Chemical Technology of Inorganic Materials, Johannes Kepler University Linz, 4040 Linz, Austria; 이이이.org/00000001-8930-1560

Jan Philipp Kollender - Institute of Chemical Technology of Inorganic Materials, Johannes Kepler University Linz, 4040 Linz, Austria; EMPA, Laboratory for Joining Technologies \& Corrosion, Swiss Federal Laboratories for Materials Science and Technology, 8600 Dübendorf, Switzerland

Heiko Groiss - Christian Doppler Laboratory for Nanoscale Phase Transformations, Center of Surface and Nanoanalytics, Johannes Kepler University Linz, 4040 Linz, Austria

Achim Walter Hassel - Institute of Chemical Technology of Inorganic Materials and Christian Doppler Laboratory for Combinatorial Oxide Chemistry at the Institute of Chemical Technology of Inorganic Materials, Johannes Kepler University Linz, 4040 Linz, Austria; (1) orcid.org/00000002-9816-6740

Complete contact information is available at: https://pubs.acs.org/10.1021/acsami.0c22211

\section{Author Contributions}

A.M. and C.C.M. had equal contributions. The manuscript was written through contributions of all authors. All authors have given approval to the final version of the manuscript.

\section{Funding}

Department for Human Resource Development, Gender and Diversity Management, Johannes Kepler University Linz, Christian Doppler Research Association, Austrian Federal Ministry for Digital and Economic Affairs, National Foundation for Research, Technology and Development.

\section{Notes}

The authors declare no competing financial interest.

\section{ACKNOWLEDGMENTS}

The financial support granted to S.R. through Iris Fischlmayr scholarship from Johannes Kepler University Linz is gratefully acknowledged. The authors are thankful to Tobias Zenger and Martin Eibelhuber from the EV Group E. Thallner GmbH, St. Florian am Inn, Austria for their contribution in photolithographical patterning of shadow masks on $\mathrm{SiO}_{2}$ wafers. TEM sample preparation by $\mathrm{K}$. Stadlmann is gratefully acknowledged. The financial support by the Austrian Federal Ministry for Digital and Economic Affairs, the National Foundation for Research, Technology and Development, and the Christian Doppler Research Association is gratefully acknowledged for financing "Christian Doppler Laboratory for Nanoscale Phase Transformations" and "Christian Doppler Laboratory for Combinatorial Oxide Chemistry”.

\section{ABBREVIATIONS}

SEM, scanning electron microscopy 
SEDX, scanning energy dispersive X-ray spectroscopy $\mathrm{PEN}$, polyethylene naphthalate

XRD, X-ray diffraction

TEM, transmission electron microscopy

\section{REFERENCES}

(1) Kim, M.-G.; Alrowais, H.; Brand, O. Wearable Electronics: Four Degrees-of-Freedom Direct Writing of Liquid Metal Patterns on Uneven Surfaces. Adv. Electron. Mater. 2018, 4, 1700434.

(2) Han, L.; Cui, S.; Yu, H.-Y.; Song, M.; Zhang, H.; Grishkewich, N.; Huang, C.; Kim, D.; Tam, K. M. C. Self-Healable Conductive Nanocellulose Nanocomposites for Biocompatible Electronic Skin Sensor Systems. ACS Appl. Mater. Interfaces 2019, 11, 44642-44651.

(3) Kaltenbrunner, M.; Sekitani, T.; Reeder, J.; Yokota, T.; Kuribara, K.; Tokuhara, T.; Drack, M.; Schwödiauer, R.; Graz, I.; BauerGogonea, S.; Bauer, S.; Someya, T. An Ultra-Lightweight Design for Imperceptible Plastic Electronics. Nature 2013, 499, 458-463.

(4) Jin, H.; Abu-Raya, Y. S.; Haick, H. Advanced Materials for Health Monitoring with Skin-Based Wearable Devices. Adv. Healthcare Mater. 2017, 6, 1700024.

(5) Lacour, S. P.; Courtine, G.; Guck, J. Materials and Technologies for Soft Implantable Neuroprostheses. Nat. Rev. Mater. 2016, 1, 16063.

(6) Coyle, S.; Majidi, C.; LeDuc, P.; Hsia, K. J. Bio-inspired Soft Robotics: Material Selection, Actuation, and Design. Extreme Mech. Lett. 2018, 22, 51-59.

(7) Wu, S.; Ze, Q.; Zhang, R.; Hu, N.; Cheng, Y.; Yang, F.; Zhao, R. Symmetry-Breaking Actuation Mechanism for Soft Robotics and Active Metamaterials. ACS Appl. Mater. Interfaces 2019, 11, 4164941658.

(8) Siket, C. M.; Tillner, N.; Mardare, A. I.; Reuveny, A.; Grill, C. D.; Hartmann, F.; Kettlgruber, G.; Moser, R.; Kollender, J. P.; Someya, T.; Hassel, A. W.; Kaltenbrunner, M.; Bauer, S. Direct Writing of Anodic Oxides for Plastic Electronics. npj Flexible Electron. 2018, 2, 23.

(9) Someya, T.; Bao, Z.; Malliaras, G. G. The Rise of Plastic Bioelectronics. Nature 2016, 540, 379-385.

(10) Libanori, R.; Erb, R. M.; Reiser, A.; Le Ferrand, H.; Süess, M. J.; Spolenak, R.; Studart, A. R. Stretchable Heterogeneous Composites with Extreme Mechanical Gradients. Nat. Commun. 2012, 3, 1265.

(11) Nasirifar, N.; LeDuc, P. R.; Fedder, G. K. Material Gradients in Stretchable Substrates toward Integrated Electronic Functionality. Adv. Mater. 2016, 28, 3584-3591.

(12) Nassar, J. M.; Rojas, J. P.; Hussain, A. M.; Hussain, M. M. From Streachable to Reconfigurable Inorganic Electronics. Extreme Mech. Lett. 2016, 9, 245-268.

(13) Kim, D. H.; Rogers, J. A. Stretchable Electronics: Materials Strategies and Devices. Adv. Mater. 2008, 20, 4887-4892.

(14) Dickey, M. D. Stretchable and Soft Electronics using Liquid Metals. Adv. Mater. 2017, 29, 1606425.

(15) Dickey, M. D. Emerging Applications of Liquid Metals Featuring Surface Oxides. ACS Appl. Mater. Interfaces 2014, 6, 18369-18379.

(16) Hirsch, A.; Michaud, H. O.; Gerratt, A. P.; de Mulatier, S.; Lacour, S. P. Intrinsically Stretchable Biphasic (Solid-Liquid) Thin Metal Films. Adv. Mater. 2016, 28, 4507-4512.

(17) Hirsch, A.; Lacour, S. P. A Method to Form Smooth Films of Liquid Metal Supported by Elastomeric Substrate. Adv. Sci. 2018, 5, 1800256.

(18) Drack, M.; Graz, I.; Sekitani, T.; Someya, T.; Kaltenbrunner, M.; Bauer, S. An Imperceptible Plastic Electronic Wrap. Adv. Mater. 2014, 27, 34-40.

(19) Hammock, M. L.; Chortos, A.; Tee, B. C.-K.; Tok, J. B.-H.; Bao, Z. 25th anniversary article: The Evolution of Electronic Skin (eskin): A Brief History, Design Considerations, and Recent Progress. Adv. Mater. 2013, 25, 5997-6038.

(20) Yoon, S.-M.; Jung, S.-W.; Yang, S.; Ko Park, S.-H.; Yu, B.-G.; Ishiwara, $\mathrm{H}$. Bending Characteristics of Ferroelectric Poly(vinylidene
Fluoride Trifluoroethylene) Capacitors Fabricated on Flexible Polyethylene Naphthalate Substrate. Curr. Appl. Phys. 2011, 11, S219-S224.

(21) Blech, I. A.; Herring, C. Stress Generation by Electromigration. Appl. Phys. Lett. 1976, 29, 131-133.

(22) Brody, T. P. The Thin Film Transistor-A Late Flowering Bloom. IEEE Trans. Electron Devices 1984, 31, 1614-1628.

(23) Seith, W.; Wever, H. Über einen neuen Effekt bei der Elektrolytischen Überführung in festen Legierungen. Z. Elektrochem. 1953, 57, 891-900.

(24) Tao, J.; Cheung, N. W.; Hu, C. An Electromigration Failure Model for Interconnects under Pulsed and Bidirectional Current Stressing. IEEE Trans. Electron Devices 1994, 41, 539-545.

(25) Liang, C.-L.; Lee, S.-W.; Lin, K.-L. The Mechanism of an Increase in Electrical Resistance in $\mathrm{Al}$ Thin Film Induced by Current Stressing. Thin Solid Films 2017, 636, 164-170.

(26) Tu, K. N.; Liu, Y.; Li, M. Effect of Joule Heating and Current Crowding on Electromigration in Mobile Technology. Appl. Phys. Rev. 2017, 4, 011101.

(27) Kato, T.; Suzuki, K.; Miura, H. Effect of the Crystallinity on the Electromigration Resistance of Electroplated Copper Thin-Film Interconnections. J. Electron. Packag. 2017, 139, 020911.

(28) Blech, I. A. Electromigration in Thin Aluminum Films on Titanium Nitride. J. Appl. Phys. 1976, 47, 1203-1208.

(29) Zhong, X.; Yu, S.; Chen, L.; Hu, J.; Zhang, Z. Test Methods for Electrochemical Migration: a Review. J. Mater. Sci.: Mater. Electron. 2017, 28, 2279-2289.

(30) Maekawa, K.; Mori, K.; Suzumura, N.; Honda, K.; Hirose, Y.; Asai, K.; Uedono, A.; Kojima, M. Impact of $\mathrm{Al}$ in $\mathrm{Cu}$ Alloy Interconnects on Electro and Stress Migration Reliabilities. Microelectron. Eng. 2008, 85, 2137.

(31) Yokogawa, S.; Tsuchiya, H.; Kakuhara, Y.; Kikuta, K. Analysis of Al Doping Effects on Resistivity and Electromigration of Copper Interconnects. IEEE Trans. Device Mater. Reliab. 2008, 8, 216-221.

(32) Ravandi, S.; Mardare, C. C.; Zenger, T.; Eibelhuber, M.; Hassel, A. W.; Mardare, A. I. Samarium Influence on Current Induced Atomic Displacement in Aluminium and Copper Combinatorial Thin Film Alloys. Thin Solid Films 2020, 702, 137949.

(33) Murray, J. L. The Al-Ga (Aluminum-Gallium) System. J. Phase Equilib. 1983, 4, 183-190.

(34) Hugo, R. C.; Hoagland, R. G. The Kinetics of Gallium Penetration into Aluminum Grain Boundaries-in situ TEM Observations and Atomistic Models. Acta Mater. 2000, 48, 19491957.

(35) Hagström, J.; Mishin, O. V.; Hutchinson, B. Gallium Enhanced Microscopy for Revealing Grain Boundaries and Dislocation Subboundaries in Aluminium Alloys. Scr. Mater. 2003, 49, 10351040.

(36) Straumal, B.; Gust, W.; Molodov, D. Tie Lines of the Grain Boundary Wetting Phase Transition in the Al-Sn System. J. Phase Equilib. 1994, 15, 386-391.

(37) Ludwig, W.; Bellet, D. Penetration of Liquid Gallium into Grain Boundaries of Aluminum: A Synchrotron Radiation Microtomographic Investigation. Mater. Sci. Eng., A 2000, 281, 198-203.

(38) Ziebarth, J. T.; Woodall, J. M.; Kramer, R. A.; Choi, G. Liquid Phase-Enabled Reaction of Al-Ga and Al-Ga-In-Sn Alloys with Water. Int. J. Hydrogen Energy 2011, 36, 5271-5279.

(39) Senel, E.; Walmsley, J. C.; Diplas, S.; Nisancioglu, K. Liquid Metal Embrittlement of Aluminium by Segregation of Trace Element Gallium. Corr. Sci. 2014, 85, 167-173.

(40) Kravchenko, O. V.; Semenenko, K. N.; Bulychev, B. M.; Kalmykov, K. B. Activation of Aluminum Metal and its Reaction with Water. J. Alloys Compd. 2005, 397, 58-62.

(41) Jendrzejczyk-Handzlik, D.; Fitzner, K.; Gierlotka, W. On the $\mathrm{Cu}-\mathrm{Ga}$ System: Electromotive Force Measurement and Thermodynamic Reoptimization. J. Alloys Compd. 2015, 621, 287-294.

(42) Du, H.; Champness, C. H.; Shih, I.; Cheung, T. Growth of Bridgman Ingots of $\mathrm{CuGa}_{\mathrm{x}} \mathrm{In}_{1-\mathrm{x}} \mathrm{Se}_{2}$ for Solar Cells. Thin Solid Films 2005, 480-481, 42-45. 
(43) Bernstein, L. R. Mechanisms of Therapeutic Activity for Gallium. Pharmacol. Rev. 1998, 50, 665-682.

(44) Ivanoff, C. S.; Ivanoff, A. E.; Hottel, T. L. Gallium poisoning: A Rare Case Report. Food Chem. Toxicol. 2012, 50, 212-215.

(45) Jeong, S. H.; Hagman, A.; Hjort, K.; Jobs, M.; Sundqvist, J.; Wu, Z. Liquid Alloy Printing of Microfluidic Stretchable Electronics. Lab Chip 2012, 12, 4657-4664.

(46) Park, C. W.; Moon, Y. G.; Seong, H.; Jung, S. W.; Oh, J.-Y.; Na, B. S.; Park, N.-M.; Lee, S. S.; Im, S. G.; Koo, J. B. PhotolithographyBased Patterning of Liquid Metal Interconnects for Monolithically Integrated Stretchable Circuits. ACS Appl. Mater. Interfaces 2016, 8, 15459-15465.

(47) Khan, M. R.; Bell, J.; Dickey, M. D. Localized Instabilities of Liquid Metal Films via In-Plane Recapillarity. Adv. Mater. Interfaces 2016, 3, 1600546.

(48) Liu, S.; Sweatman, K.; McDonald, S.; Nogita, K. Ga-Based Alloys in Microelectronic Interconnects: A Review. Materials 2018, $11,1384$.

(49) Michaud, H. O.; Lacour, S. P. Liquid Electromigration in Gallium-based Biphasic Thin Films. APL Mater. 2019, 7, 031504.

(50) Li, R.; Sun, G.; Xu, L. Anomalous properties and the liquidliquid phase transition in gallium. J. Chem. Phys. 2016, 145, 054506.

(51) Ravandi, S.; Zenger, T.; Eibelhuber, M.; Hassel, A. W.; Mardare, A. I. Customized 2D Structures for High Throughput Electromigration Measurements. Phys. Status Solidi A 2019, 216, 1800869.

(52) Williams, D. B.; Carter, C. B. Transmission Electron Microscopy A Textbook for Materials Science; Springer US, 2009; p 775.

(53) Odusote, Y. A.; Jabar, J. M.; Adelakun, A. O. Thermodynamics and Vacuum Distillation Studies of Liquid Al-Ga and In-Sn Alloys. Phys. Chem. Liq. 2018, 56, 452-464.

(54) Li, J.-B.; Ji, L. N.; Liang, J. K.; Zhang, Y.; Luo, J.; Li, C. R.; Rao, G. H. A Thermodynamic Assessment of the Copper-Gallium System. Calphad 2008, 32, 447-453.

(55) Ponweiser, N.; Lengauer, C. L.; Richter, K. W. Re-investigation of Phase Equilibria in the System $\mathrm{Al}-\mathrm{Cu}$ and Structural Analysis of the High-Temperature Phase $\eta_{1}-\mathrm{Al}_{1-\delta} \mathrm{Cu}$. Intermetallics 2011, 19, 1737-1746.

(56) Liu, S.; McDonald, S.; Gu, Q.; Matsumura, S.; Qu, D.; Sweatman, K.; Nishimura, T.; Nogita, K. Properties of $\mathrm{CuGa} 2$ Formed Between Liquid $\mathrm{Ga}$ and $\mathrm{Cu}$ Substrates at Room Temperature. J. Electron. Mater. 2020, 49, 128-139.

(57) Liu, S.; Zeng, G.; Yang, W.; McDonald, S.; Gu, Q.; Matsumura, S.; Nogita, K. Interfacial Reactions between $\mathrm{Ga}$ and $\mathrm{Cu}-10 \mathrm{Ni}$ Substrate at Low Temperature. ACS Appl. Mater. Interfaces 2020, 12, 21045-21056.

(58) Liu, S.; Yang, W.; Kawami, Y.; Gu, Q.; Matsumura, S.; Qu, D.; McDonald, S.; Nogita, K. Effects of $\mathrm{Ni}$ and $\mathrm{Cu}$ Antisite Substitution on the Phase Stability of $\mathrm{CuGa} 2$ from Liquid $\mathrm{Ga} / \mathrm{Cu}-\mathrm{Ni}$ Interfacial Reaction. ACS Appl. Mater. Interfaces 2019, 11, 32523-32532.

(59) Mardare, A. I.; Kaltenbrunner, M.; Sariciftci, N. S.; Bauer, S.; Hassel, A. W. Ultra-thin Anodic Alumina Capacitor Films for Plastic Electronics. Phys. Status Solidi A 2012, 209, 813-818. 